\title{
APPLICATIONS OF CONTINUOUS SNOWPACK TEMPERATURE MONITORING
}

by

Peter J. Youngblood

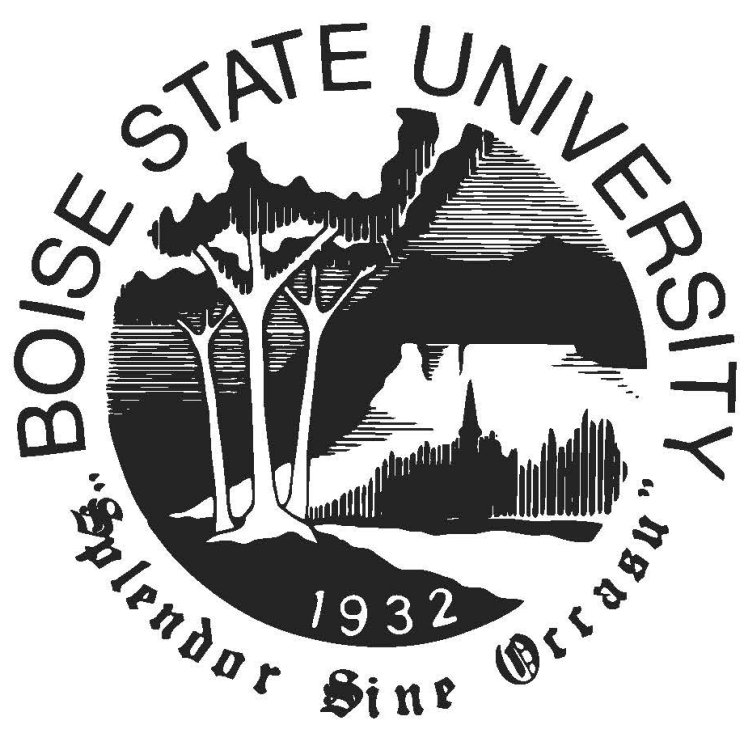

A thesis

submitted in partial fulfillment

of the requirements for the degree of

Master of Science in Hydrologic Sciences

Boise State University

August 2020 
(C) 2020

Peter J. Youngblood

ALL RIGHTS RESERVED 
BOISE STATE UNIVERSITY GRADUATE COLLEGE

\title{
DEFENSE COMMITTEE AND FINAL READING APPROVALS
}

\author{
of the thesis submitted by
}

\author{
Peter J. Youngblood
}

Thesis Title: Applications of Continuous Snowpack Temperature Monitoring Date of Final Oral Examination: $\quad 22$ June 2020

The following individuals read and discussed the thesis submitted by student Peter J. Youngblood, and they evaluated the student's presentation and response to questions during the final oral examination. They found that the student passed the final oral examination.

HP Marshall Ph.D. Chair, Supervisory Committee

James McNamara Ph.D. Member, Supervisory Committee

Matt Kohn Ph.D. Member, Supervisory Committee

The final reading approval of the thesis was granted by HP Marshall Ph.D., Chair of the Supervisory Committee. The thesis was approved by the Graduate College. 


\section{DEDICATION}

I dedicate this to my parents for their never-ending support and encouragement. I also dedicate this to anyone striving to better the world. Keep your motives true, focus on becoming a better individual, and find ways to give back to your community. I write this as a reminder to you, but also myself. 


\section{ACKNOWLEDGMENT}

This project wouldn't have been possible without the support of my graduate advisory committee, Thomas Othiem, and Pamella Aishlan-Cedillo; the latter two provided critical support throughout the manufacturing and design process, which enabled us to collect such a robust dataset in 2019. I also give thanks to Thomas Black and Charlie Luce, who shared their design for this instrument. This project is unique because it's received input from many agencies, including the Idaho Department of Transportation, USDA-NRCS, USFS, as well as hydrologists and geophysicists from Boise State University. The results are collaboration and the culmination of many years spent in development. 


\section{ABSTRACT}

Predicting metamorphism within seasonal snowpacks is critical for avalanche forecasting and runoff timing as it relates to water supply management. Snowpack temperature gradients play a key role in snow metamorphism, and their magnitude controls how snow strength changes; therefore, they are of interest to avalanche forecasters. Before major melt, the snowpack must warm to isothermal conditions at $0^{\circ} \mathrm{C}$. Measuring this transition from warming to the ripening phase could help improve our current models for runoff timing. Measuring snowpack temperature gradients is currently a non-automated process that requires disturbance of the snow profile, and only gives a snapshot in time of the temperature conditions. Here we demonstrate an automated method to monitor in situ snowpack temperature using a thermocouple array, co-located with the Banner Summit SNOTEL site in central Idaho. Showing the location and duration of critical temperature gradients helps avalanche forecasters detect warning signs related to possible facet formation. During the 2019 winter, we observed large temperature gradients in the bottom $20 \mathrm{~cm}$ of the snowpack, with the gradient falling below critical $\left(<0.1^{\circ} \mathrm{C} / \mathrm{cm}\right)$ by early January. Critical gradients were observed near the surface throughout the winter, and temperatures were within \pm $0.06{ }^{\circ} \mathrm{C}$ of the melting point when the snowpack became isothermal in the spring. We anticipate this dataset will inform snowpack energy balance models and aid in the prediction of avalanche hazards and runoff timing. 


\section{TABLE OF CONTENTS}

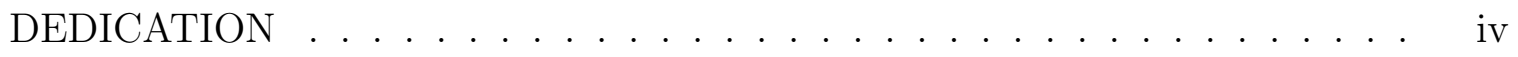

ACKNOWLEDGMENT . . . . . . . . . . . . . . . . . v v

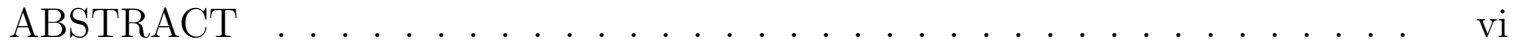

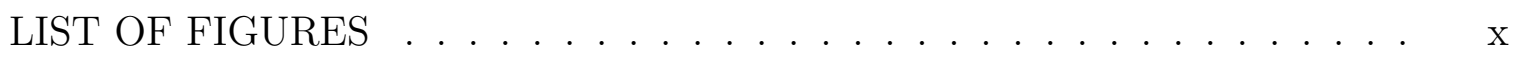

NOMENCLATURE ...................... . . . . . . .

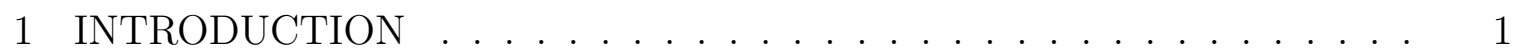

2 LITERATURE REVIEW . . . . . . . . . . . . . . . . . 8

2.1 Thermocouple Array . . . . . . . . . . . . . . . . . 8

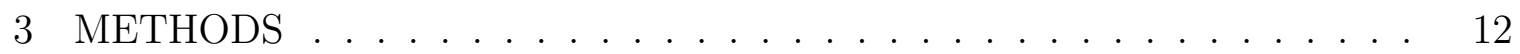

3.1 Thermocouple Array . . . . . . . . . . . . . . . . . . . . 12

3.2 Temperature Gradient Analysis . . . . . . . . . . . . . . . . 14

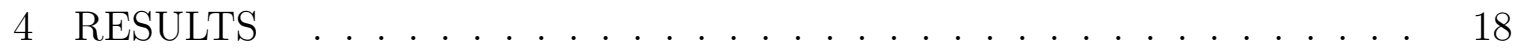

4.1 Thermocouple Array . . . . . . . . . . . . . . . . 18

4.2 Temperature Gradient Analysis . . . . . . . . . . . . . 25 


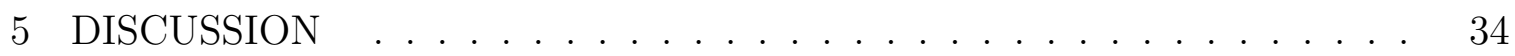

5.1 Temperature Gradient Analysis . . . . . . . . . . . . . . . . . 34

5.2 Isothermal Snowpack and Runoff Timing . . . . . . . . . . . . . 35

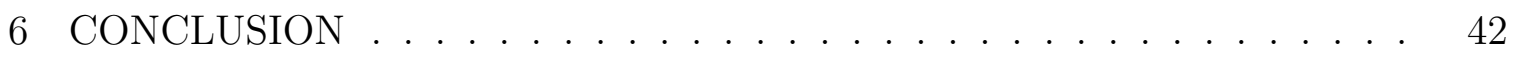

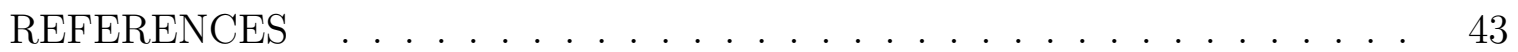

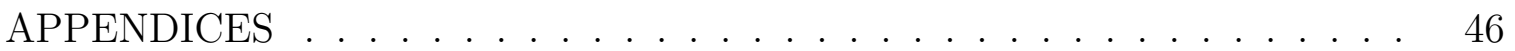

A TIME-LAPSE MOVIES . . . . . . . . . . . . . . . . 47

A.1 Early Season . . . . . . . . . . . . . . . . . 48

A.2 Mid Season . . . . . . . . . . . . . . . . . . . . . . . . . 48

A.3 Late Season - Isothermal Development . . . . . . . . . . . . . . . . . 48

B BSTA TECHNICAL DETAILS . . . . . . . . . . . . . . 49

B.1 Parts List . . . . . . . . . . . . . . . . . . . 50

B.2 CR1000 Code . . . . . . . . . . . . . . . . 50

B.3 Structure Design . . . . . . . . . . . . . . . 50

C DATA \& ANALYSIS . . . . . . . . . . . . . . . . . 52

C.1 Water Year 2019 Data . . . . . . . . . . . . . . . . 53

C.2 Water Year 2020 Data . . . . . . . . . . . . . . 53

C.2.1 Raw Transmitted Data . . . . . . . . . . . . 53

C.2.2 2020 Data Intake (Python) . . . . . . . . . . . . . 53

C.3 Analysis . . . . . . . . . . . . . . . . . . 53

C.3.1 Temperature Gradient Analysis . . . . . . . . . . . 53 
C.3.2 Uncertainty Analysis . . . . . . . . . . . . . . 54

C.3.3 Isothermal Snowpack and Runoff Timing . . . . . . . . . . . . 54

D STABLE WATER ISOTOPE ANALYSIS . . . . . . . . . . . . . 55

D.1 Literature Review . . . . . . . . . . . . . . . . . 56

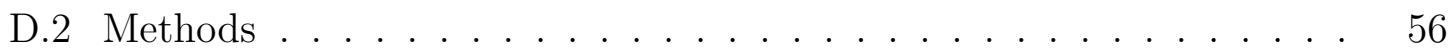

D.3 Results. . . . . . . . . . . . . . . . . . . 59

D.4 Discussion . . . . . . . . . . . . . . . . . . 62

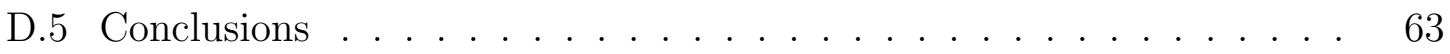




\section{LIST OF FIGURES}

1.1 Figure from Arenson et al. (2015) showing the variation of thermal conductivity with density, the range of data in the literature summarized by Sturm et al. (1997), and several proposed models. . . . . . . . .

1.2 Temperature of snow-ground interface during the 2019 period of record. The ground remains at, or near the freezing point for the whole season

2.1 An ultrasonic sensor and a SM4 snow depth sensor covered with icing. The SM4 is attached to the upper stanchion. . . . . . . . . . 10

3.1 Picture of the instrument installed at Banner Creek Summit. . . . . . 14

3.2 Examples of a first order regression fit to the upper $25 \mathrm{~cm}$ and lowest $20 \mathrm{~cm}$. The snow surface, as measured by the Banner Summit SNOTEL site is the horizontal, dark gray line which marks the upper limit (snow depth) of the upper $25 \mathrm{~cm}$ interval. The two figures are from two time periods during 2019 and illustrate differences between a shallow and a deeper snowpack. Snow accumulation on the temperature sensors is likely occurring between $120-145 \mathrm{~cm}$ in the figure on the right. . . . 
4.1 Plot of temperature profile in snowpack vs. time for the thermocouple array in the Banner Summit study area. The gradient in colors from red to blue designates a range in temperatures from 0 to $-10{ }^{\circ} \mathrm{C}$. The white line shows snow depth as measured by the adjacent SNOTEL instrument array. The pink line shows our inferred snow depth based on temperature differences between thermocouples (no temperature difference indicates that the sensors are above the snow surface). The pink line is consistently above the white line, indicating snow bridging.

4.2 Photograph of instrument array on 01/18/19 showing major snow accumulation (bridging) between the two main support posts. . . . . . .

4.3 Subplot 1: Temperature measurement between $0 \mathrm{~cm}$ up to $20 \mathrm{~cm}$ above ground. At this point, they are all buried in snow. Subplot 2: Temperature measurements for the thermocouples between $25 \mathrm{~cm}$ and $55 \mathrm{~cm}$ above ground. Subplot 3: Temperature measurements for the thermocouples between $55 \mathrm{~cm}$ and $85 \mathrm{~cm}$ above ground. At the begining of the time series, all thermocouples are above the snow surface and read a consistent temperature. Starting December 19th, there is snow accumulation that begins to bury these sensors and the become insulated from the strong diurnal temperature swings. . . . . . . . . . . . . . . 21

4.4 Continuous plot of the temperature measurements between December 1 - 30. The white line is snow depth recorded by an acoustic sensor at the nearby SNOTEL site. . . . . . . . . . . . . . . 
4.6 Histogram of the temperature measurements taken during an isothermal snowpack in 2019 which shows a standard deviation of \pm 0.06

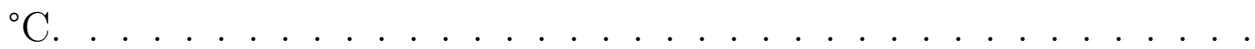

4.7 Time series of SWE at Banner summit plotted with the precipitation at the Banner Summit SNOTEL site. . . . . . . . . . . . .

4.8 The daily temperature range for each thermocouple between $-10 \mathrm{~cm}$ to $135 \mathrm{~cm}$ showing the increase in temperature range directly following major snowmelt. ................... . . 25

4.9 Subplot 1: Temperature gradient in top 25cm of snowpack during 2019 period of record. Gradients in the shaded red area are considered greater than critical and destructive metamorphism is likely to occur. Subplot 2: Temperature gradient in lowest $20 \mathrm{~cm}$ of snowpack during 2019 period of record. . . . . . . . . . . . . . . . . . . . 27

4.10 Heatmap of data collected by BSTA during December. The solid white line indicates snow depth measured by the Banner Summit SNOTEL

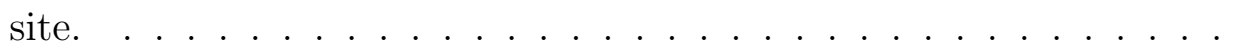

4.11 Relative density histogram of temperature gradients in the upper $25 \mathrm{~cm}$ of the snowpack during December. Gradients in the shaded red area are considered greater than critical and are facet forming. . . . . . . . 28

4.12 Relative density histogram of temperature gradients in the lowest $20 \mathrm{~cm}$ of the snowpack during December. . . . . . . . . . . . .

4.13 Relative density histogram of temperature gradients in the upper $25 \mathrm{~cm}$ of the snowpack during February. . . . . . . . . . . . . . . 
4.14 Relative density histogram of temperature gradients in the lowest $20 \mathrm{~cm}$ of the snowpack during February. . . . . . . . . . . . . . . . 30

4.15 Relative density histogram of temperature gradients in the upper $25 \mathrm{~cm}$ of the snowpack during March. . . . . . . . . . . . . . . . 30

4.16 Relative density histogram of temperature gradients in the lowest $20 \mathrm{~cm}$ of the snowpack during March. . . . . . . . . . . . . . . . . 31

4.17 Results of the Monte-Carlo Simulation of temperature gradient analysis based on $\pm 0.06{ }^{\circ} \mathrm{C}$ error on thermocouple measurements. . . . . . . . 32

4.5 Hourly average temperature for each thermocouple between $-10 \mathrm{~cm}$ to $165 \mathrm{~cm} \ldots \ldots \ldots \ldots \ldots \ldots \ldots$

5.1 Progression of snowpack temperatures leading to isothermal conditions starting March 31. . . . . . . . . . . . . . . . .

5.2 A zoomed-in sub-plot of data shown in Figure 5.1. This figure shows March 30 - 31 and the smallest range of thermocouple measurements which occurs on March 31. . . . . . . . . . . . . . .

5.3 SWE and Snow Density during the warming, ripening, and output phases at Banner Summit. This figre Shows that significant loss in SWE occured after the snowpack reached $\sim 40 \%$ density. . . . . . .

5.4 Unregulated streamflow data from a USGS stream gauge near Banner Summit. This figure shows how the observed streamflow departs from normal conditions shortly after the snowpack at our study site goes isothermal. . . . . . . . . . . . . . . . . 
D.1 Picture of the sampling pit used on December 18, 2018 illustrating where duplicates were sampled with about $0.5 \mathrm{~m}$ spacing as represented by the shaded boxes with black lines. The red and green dots are observed ice layers, and storm layer surfaces. . . . . . . . . . . . . 58

D.2 Picture of the sampling pit used on March 17th, 2019 showing where triplicates were collected. . . . . . . . . . . . . .

D.3 Stable water isotope composition for samples taken on December 18, 2018. There is strong agreement in the lowest $10 \mathrm{~cm}$, but the profiles diverge moving up through the snowpack. The largest difference between profiles is right around $40 \mathrm{~cm}$. . . . . . . . . . . . . . 61

D.4 Stable water isotope composition for samples taken on March 17, 2019. 62

D.5 Oxygen isotopes sampled throughout the 2019 winter season. . . . . . 64 


\section{NOMENCLATURE}

$Q_{\text {cc }} \quad$ The cold content of a snowpack

$Q_{\mathrm{m} 2}$ The net energy required to complete the ripening phase

$\lambda_{f} \quad$ The latent heat of fusion

$\rho_{\mathrm{s}} \quad$ The density of snow

$\rho_{\mathrm{w}} \quad$ The density of water

$\rho_{s} \quad$ The bulk density of a snowpack

$\theta_{\text {ret }}$ The volumetric water content

$h_{\mathrm{s}} \quad$ Snowdepth 


\section{CHAPTER 1:} INTRODUCTION

Snow in Idaho serves a critical role not only for recreationists but for the state economy. A majority of irrigated agriculture in Idaho relies on surface water managed by a series of canals and reservoir systems. A majority of this water comes as snow during the winter months and is then stored in reservoirs for use during the growing season. Because of this, water managers in Idaho are actively looking for ways to better predict snowmelt runoff. Also, snow and snowmelt can have significant impacts on infrastructure and transportation throughout the state. Avalanches in central Idaho cause frequent closures on Idaho State Highway 21 and there is a strong push by local avalanche forecasters to better measure temperature conditions of the snowpack leading up to elevated avalanche hazards. By looking at specific snowpack characteristics, it is possible to gain insight into conditions leading to avalanche hazards, floods caused by rain on snow events, and significant runoff.

The physical properties of snow play an essential role in avalanche prediction. Under the right conditions, temperature gradients within a snowpack drive vapor migration. As vapor migrates through and out of the snowpack, it changes the snow's microstructure and can lead to a substantial water loss of $15 \%$ - 20\% (Hood et al., 1999; Marks and Dozier, 1992; Kattelmann and Elder, 1991). Continuous monitoring of snowpack temperature gradients is valuable for avalanche forecasting because 
the development of weak, faceted layers, such as depth hoar, depends on a temperature gradient. The rate at which this process (called kinetic metamorphism) occurs depends on several different factors, including the initial snow characteristics, magnitude and duration of temperature gradients, vapor barriers caused by ice layers, and the snowpack's cold content (see equation 1.1)(Sommerfeld and LaChapelle, 1970; Colbeck, 1983). Although this is a continuous process that occurs over a wide range of temperature gradients, the critical gradient to produce faceted forms in alpine snow is about $0.1^{\circ} \mathrm{C} / \mathrm{cm}$ (McClung and Schaerer, 2009). When temperature gradients are less than critical, the snow undergoes primarily equillibrium metamorphism and water molecules move mainly by vapor diffusion to new positions that decrease the surface free energy (Sommerfeld and LaChapelle, 1970). Thus, equillibrium metamorphism is controlled by surface convexities, and leads to rounding and bonds forming between individual snow grains. Both time and temperature are significant factors in determining the stage of metamorphism. If the snow is very cold, it will change slowly; and if it's close to the freezing point, it can change rapidly. In the case of depth hoar, if the critical temperature gradient no longer persists, the snow will undergo equillibrium metamorphism, which breaks down many of its facets (Sommerfeld and LaChapelle, 1970).

It is important to consider the thermal conductivity of snow which plays an important role in the transfer of energy within the snowpack. The thermal properties of snow vary with density, microstructure, and temperature (Arenson et al., 2015). The thermal conductivity of snow ranges from 0.04 to $1 \mathrm{~W} / \mathrm{m} / \mathrm{K}$ over the density range of $100-550 \mathrm{~kg} / \mathrm{m}^{3}$. Although thermal conductivity varies primarily with density, variations in microstructure and crystal anisotropic orientation can affect it by a fac- 


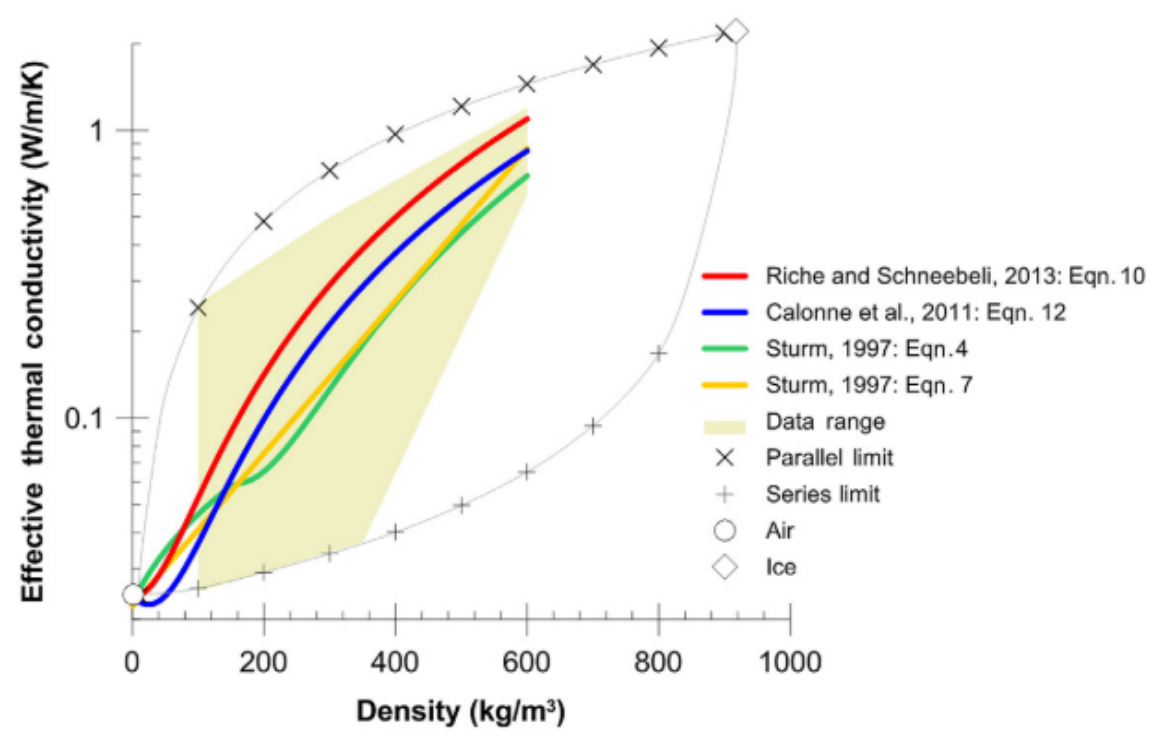

Figure 1.1: Figure from Arenson et al. (2015) showing the variation of thermal conductivity with density, the range of data in the literature summarized by Sturm et al. (1997), and several proposed models.

tor of two. Figure 1.1 shows how effective thermal conductivity increases with snow density. Thermal conductivity variations near ice layers can induce large temperature gradients that lead to faceted, weak layer formation, and can be a significant cause of avalanches (Arenson et al., 2015). Banner Summit's snowpack rarely forms ice layers because air temperatures remain below $0^{\circ} \mathrm{C}$ for the majority of the winter, which prohibits the initial melt required to form an ice layer.

Near Banner Summit in Idaho, a significant concern for avalanche forecasters is in the development of depth hoar. Depth hoar is large-grained, faceted, cup-shaped crystals near the ground and forms because of large temperature gradients within the snowpack (Akitaya, 1974). Depth hoar most commonly forms in the early season because the snowpack is shallow, and there isn't much snow insulating the lowest layers from the cold atmosphere. The geothermal heat flux keeps the snow-ground 


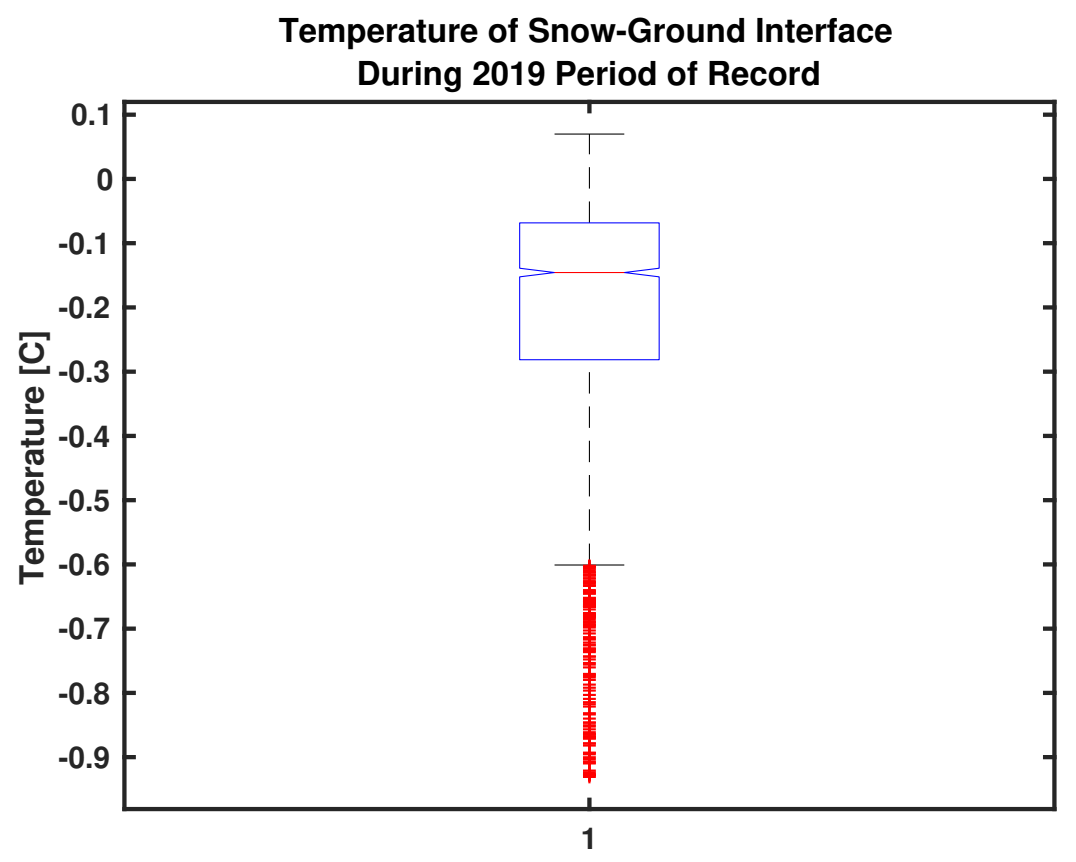

Figure 1.2: Temperature of snow-ground interface during the 2019 period of record. The ground remains at, or near the freezing point for the whole season

interface temperature very close to $0{ }^{\circ} \mathrm{C}$ (Figure 1.2). This condition combined with a shallow snowpack and cold air temperatures, leads to large sustained temperature gradients in the early season. The duration and magnitude of critical temperature gradients in the lower snowpack is not well monitored, as typically it is measured infrequently during manual snowpit observations; for example the ITD avalanche forecasters measure this gradient once per month.

Dry-snow avalanches are primarily a concern in the early to mid-winter season. As spring approaches, a snowpack temperature profile provides insight into the snowmelt process, and can indicate when wet snow avalanches are possible. There are are three primary phases a snowpack must go through to have considerable melt and runoff: 
warming, ripening, and output (Dingman, 2015). Any energy absorbed by the subfreezing snowpack during the warming phase raises its average temperature until it reaches isothermal conditions at $0^{\circ} \mathrm{C}$ (Dingman, 2015). This energy required to warm a snowpack to isothermal conditions is known as the cold content $\left(\mathrm{Q}_{\mathrm{cc}}\right)$ (Dingman, 2015), and can be calculated directly from the temperature profile:

$$
Q_{\mathrm{cc}}=-c_{\mathrm{i}} * \rho_{\mathrm{w}} * h_{\mathrm{m}} *\left(T_{\mathrm{s}}-T_{\mathrm{m}}\right)
$$

Where $c_{i}$ is the heat capacity of ice, $T_{s}$ is the average temperature of the snowpack, $\mathrm{T}_{\mathrm{m}}$ is the melting point of ice, $\rho_{\mathrm{w}}$ is the density of water, and $\mathrm{h}_{\mathrm{m}}$ is the snow water equivalent (SWE).

Once the snowpack is isothermal, it enters the ripening phase where absorbed energy melts snow, but the meltwater is retained in the snowpack by surface tension forces (Dingman, 2015). After the snowpack reaches its water holding capacity and it is "ripe," it enters the output phase where further absorption of energy produces water output (Dingman, 2015). Because isothermal conditions mark the beginning of the ripening phase, it may be possible to predict snowmelt runoff timing more accurately by measuring the snowpack's temperature profile continuously.

Snow is a prime example of the observer effect; the mere observation of a phenomenon within the snowpack inevitably changes the phenomenon. The current method for measuring the temperature profile of a snowpack is a time consuming, destructive process that is not automated. It requires someone to dig a snow pit and manually measure the snow temperature by inserting probes at equal depth intervals. Not only does this disturb the snow profile and change its characteristics, but it's a snapshot in time, while snow temperature conditions change on an hourly time scale 
in the upper part of the snowpack, and on a weekly time scale at depth. There is no continuous record of the snowpack temperature profile at Banner Summit and avalanche forecasters with the Idaho Transportation Department are interested in measuring the magnitude and duration of critical temperature gradients in the upper $25 \mathrm{~cm}$ and lowest $20 \mathrm{~cm}$ of the snowpack. They perform monthly in-situ snowpits and measure the gradient manually.

It is important to note that current technology can measure a snowpack temperature profile at a single point in space, rather than the basin scale. Although snowpack conditions can vary widely at the basin scale, the BSTA serves as a valuable tool because it may be possible to build statistical relationships between this site and a nearby basin, or avalanche starting zones. The ability to conduct statistical analysis for avalanche hazards and snowmelt runoff will come only with a continuous record from the BSTA at Banner Summit.

In this study, we continuously measure the snowpack temperature profile as it changes throughout the winter. This data further develops our understanding of temperature gradient metamorphism in snow, it provides insight into snowpack processes that lead to significant snowmelt, and helps address the following questions:

1) What is the duration and magnitude of critical temperature gradients in the upper and lower portions of the snowpack?

2) How long do critical temperature gradients persist in the lowest layers of the snowpack?

3) Can this data improve snowmelt runoff predictions?

We also present a continuous snowpack temperature monitoring system, the Banner Summit Thermocouple Array (BSTA) along with methods for analyzing temper- 
ature gradient metamorphism and melt. Results suggest this instrument is successful at measuring the temperature profile of a snowpack with an accuracy of $\pm 0.06{ }^{\circ} \mathrm{C}$ (Figure 4.6) and an uncertainty in temperature gradient estimates of $\pm 0.003{ }^{\circ} \mathrm{C} / \mathrm{cm}$ (Figure 4.17). 


\section{CHAPTER 2:}

\section{LITERATURE REVIEW}

\subsection{Thermocouple Array}

Few studies have proposed methods for continuous monitoring of the snowpack temperature profile. One successful instrument is the SM4 snowpack temperature and snow depth sensor. The NIVEXC is another instrument that has been used to record temperature profile measurements. Both of these systems are installed at avalanche starting zones and they measure temperature gradients using thermistors. In addition to these sensors designed for avalanche starting areas, Conway and Benedict (1994) created a thermistor array designed to study the infiltration of water during rain-on-snow events.

The main objective of the SM4 (Ingólfsson and Grímsdóttir, 2008) is to accurately measure snow depth in avalanche starting areas. The SM4 is series of digital thermistors mounted with a fixed $20 \mathrm{~cm}$ interval on a pole that extends through the snowpack (Fig. 2.1). The SM4 Measures snow depth by identifying thermistors buried in the snow, based on damping of temperature fluctuations that is caused by the snowpack. (Ingólfsson and Grímsdóttir, 2008) have developed an algorithm that calculates the snow depth as a function of the temperature profile. This snow depth algorithm is proving to be more reliable than acoustic snow depth sensors because it functions 
during times of snowfall and ice buildup. The main challenge regarding the algorithm is greatest when the temperature of the atmosphere approaches the temperature of the snowpack. It is typically installed in avalanche starting areas where it is coupled with ultrasonic snow depth sensors for verification. Measurements are logged with a few minute interval and are regularly transferred to a central computer through wireless GSM telephone connection. In addition to snow depth, the SM4 is being used to detect and visualize high temperature gradients within the snowpack.

Like the SM4, the NIVEXC (Barbolini et al., 2013) is designed to accurately measure snow depth in avalanche starting areas. The NIVEXC is an electronic snowpole with a vertical array of sensors. It is able to record and transmit important snow cover properties, such as total snow height, snow precipitation amounts and rates, and temperature profiles. Although the SM4 and the NIVEXC both measure the temperature profile of a snowpack, their primary objective is to indirectly measure snow depth through the temperature dampening effect caused by the snowpack. One limitation of both these products is the vertical resolution, which is only $20 \mathrm{~cm}$.

In Conway and Benedict (1994), a rectangular grid of thermistors is used to study the infiltration of water during two midwinter rain on snow events. The progress of wetting is tracked in real time by monitoring changes in the position of the zero-degree isotherm. Conway and Benedict (1994) used these methods to calculate the infiltration rate and found that infiltration was not uniform. Water penetrated through localized channels that often occupied less than $50 \%$ of the total volume of the snowpack. Their sensor was installed at 915m elevation in the Cascade Mountains near Snoqualmie Pass, Washington during 1991-1992. Measurements were made at 15-min intervals using up to 110 thermistors (Thermometrics p100DA202M) multiplexed to 


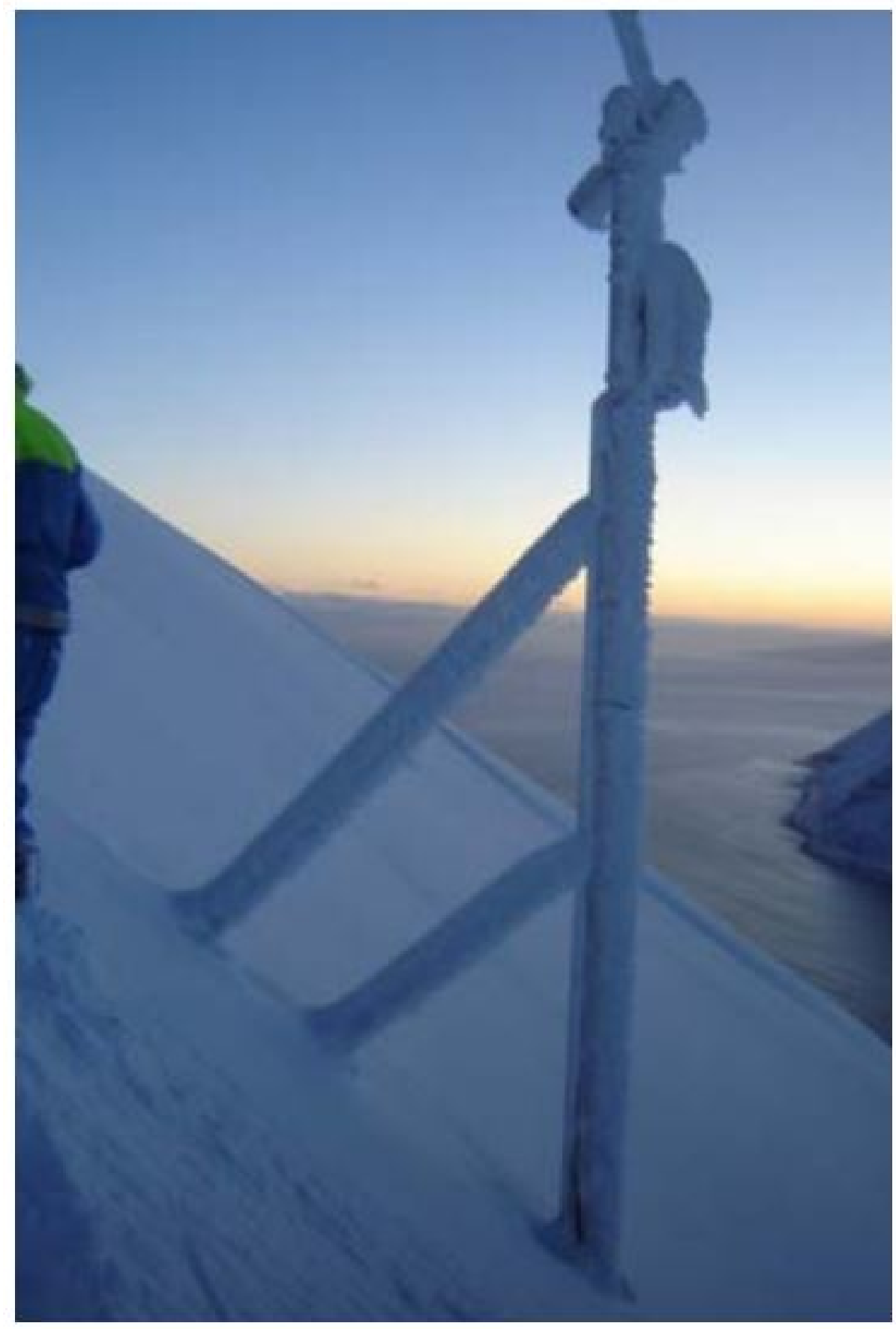

Figure 2.1: An ultrasonic sensor and a SM4 snow depth sensor covered with icing. The SM4 is attached to the upper stanchion. 
a data logger. The thermistors were wrapped in white heat-shrink tubing and white epoxy to make them waterproof and minimize heating from solar radiation. Each thermistor was field calibrated at the melting point for seasonal snow. Calibration was achieved at a time when the snow surrounding the thermistor was ripe and the electrical resistance of the thermistor had stabilized to a constant temperature. The temperature of ripe snow is $0^{\circ} \mathrm{C}$. The temperature resolution was better than \pm 0.01 ${ }^{\circ} \mathrm{C}$.

The thermistors were arranged in a vertical, rectangular grid $1.5 \mathrm{~m}$ wide and up to $2 \mathrm{~m}$ deep. Each string consisted of 11 thermistors spaced $15 \mathrm{~cm}$ apart. A parallel horizontal string set at the same height $1 \mathrm{~m}$ away supported the leads from the thermistor beads to the multiplexer. The vertical spacing between thermistors was about $15 \mathrm{~cm}$, but the thermistors were free to settle with the snowpack and the spacing decreased with time.

Charlie Luce and Tom Black with the USFS (Luce and Black, 2018) in Boise, ID constructed a thermocouple array that was installed at Bogus Basin, ID. The design for the Banner Summit Thermocouple Array is based on the thermocouple array at Bogus Basin. Charlie and Tom shared their designs and information during a meeting in October of 2018. All of the diagrams and documents that were given to us by these two can be found in Part B of the Appendix under design. 


\section{CHAPTER 3:}

\section{METHODS}

\subsection{Thermocouple Array}

Our temperature sensor is located at Banner Creek Summit in central Idaho. This location has an elevation of about 7,040 feet above sea level and is proximal to Idaho State Highway 21. The area around Banner Summit receives an average of 1.9 meters of snow each year and frequently experiences extreme low temperatures as low as $-40^{\circ} \mathrm{C}$. The $2018-2019$ winter season experienced an above-average snowfall, with a peak snow water equivalent (SWE) measured at Banner Summit at $120 \%$ of average. Site visits occurred on a biweekly basis unless weather or road closures forbid access. During each visit, data was collected from the instrument and snow samples were collected for stable water isotope analysis.

The structure of our sensor is comprised of a steel, rectangular frame with thin, metal cables running horizontally in $5 \mathrm{~cm}$ increments (Fig. 3.1). A single Omega Type $\mathrm{T}$ thermocouple is attached to each wire, a quarter distance between the two support posts, which forms a vertical array of temperature sensors spaced $5 \mathrm{~cm}$ apart, up to $2.5 \mathrm{~m}$ above the ground. There were two thermocouples buried in the soil at $10 \mathrm{~cm}$ and $5 \mathrm{~cm}$ below ground. The buried $10 \mathrm{~cm}$ thermocouple was installed directly adjacent to a thermistor (Campbell Scientific T107). The 53 thermocouples were 
multiplexed using a Campbell Scientific AM32 to a Campbell Scientific CR1000 data logger. Temperature measurements were recorded every 5 minutes. The design for this sensor came from Charlie Luce and Tom Black at the USFS and it was based off an existing sensor installed at Bogus Basin, near Boise, ID.

A Micro-Specialties satellite telemetry system was installed during the 2020 water year so that data were accessible in near-real time. Data was transmitted every six hours using an hourly average from the measurements taken the hour before each transmit. 


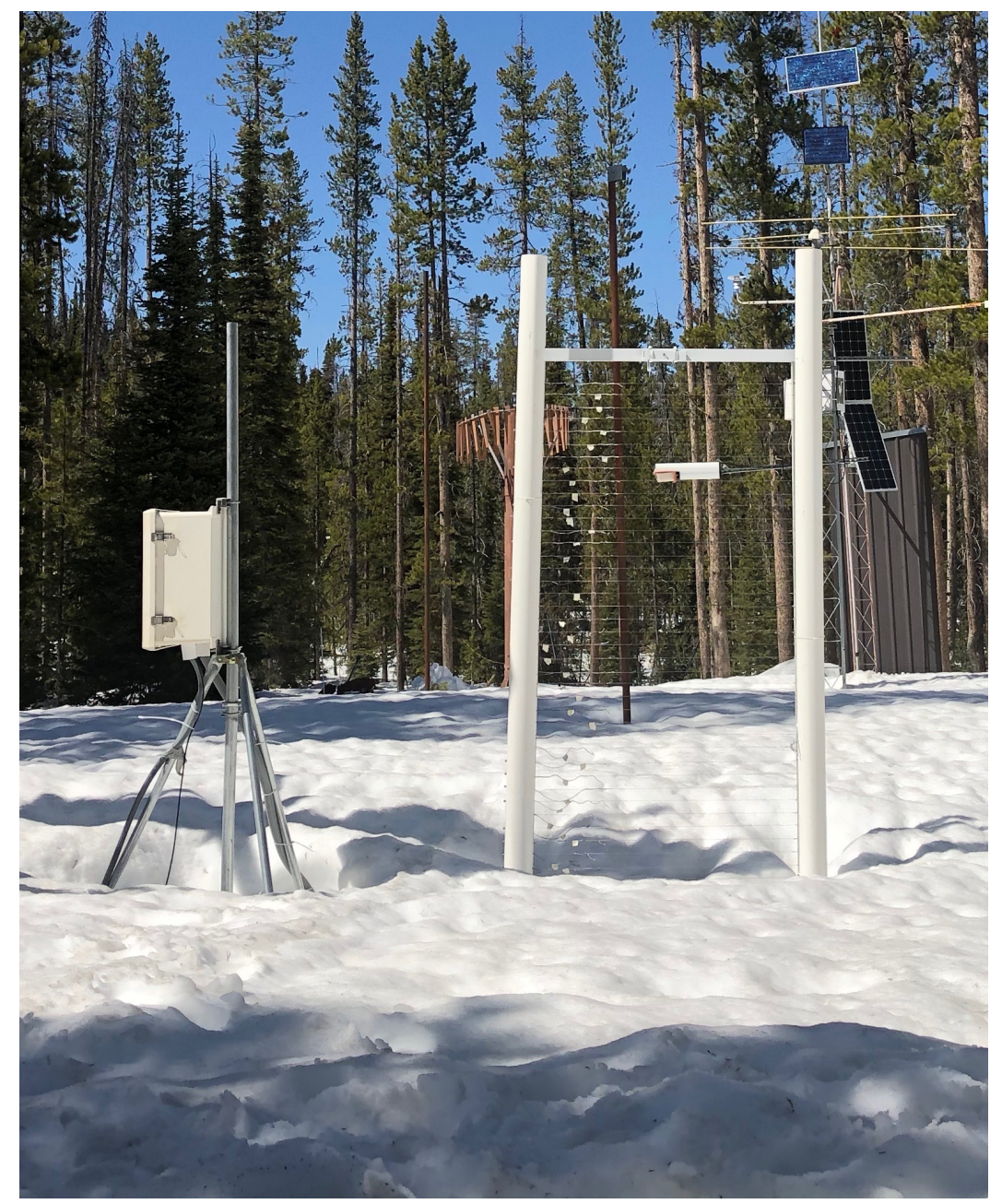

Figure 3.1: Picture of the instrument installed at Banner Creek Summit.

\subsection{Temperature Gradient Analysis}

In this analysis, we calculated the hourly average temperature gradients in the upper $25 \mathrm{~cm}$ and the lowest $20 \mathrm{~cm}$ of the snowpack using a first-order polynomial regression between depth and temperature (Figure 3.2). The slope of each polynomial, i.e., the temperature gradients during 2019 in the upper $25 \mathrm{~cm}$ and lowest $20 \mathrm{~cm}$, are shown in Figures 4.9 - 4.16. This was done in MATLAB using the built in function called 
polyfit.

There are three significant features observed from this dataset: 1) a gradient in the lower $20 \mathrm{~cm}$, which is the location of observed depth hoar and the depth over which avalanche forecasters are most interested in tracking the temperature gradient, 2) a near surface temperature gradient that changes diurnally, and 3) a snow surface temperature that is below the air temperature much of the time, likely due to longwave emission and sublimation.

Data in the upper $25 \mathrm{~cm}$ are selected because solar radiation penetrates between 20 - 30cm depth. Additionally, the Idaho Transportation Department avalanche forecasters are primarily interested in temperature gradients in the upper $25 \mathrm{~cm}$, and at the base of the snowpack. The snow surface for the upper $25 \mathrm{~cm}$ calculation is measured by the nearby SNOTEL site. Snow bridging increases the uncertainty of the temperature gradient measurements in the upper $25 \mathrm{~cm}$, but has a minimal impact on measurements deeper in the snowpack. The lowest $20 \mathrm{~cm}$ are selected because there was an observed change in snow structure in this layer during December.

The temperature gradient analysis focuses on three subsets from the 2018-2019 winter season. These three subsets are selected because they illustrate critical elements of how temperature gradients evolve throughout the season. An early-season subset between November 31 to December 28 shows large temperature gradients throughout the shallow snowpack; observations made in snowpits on these two dates indicate depth hoar formation. A mid-season subset during February shows extreme cold events and record amounts of snowfall; the lowest portion of the snowpack is well insulated and does not experience critical temperature gradients. The late-season subset during March shows the snowpack as it reaches isothermal conditions. 
Temperature gradients at the top of the snowpack change diurnally because it is not completely insulated from the air. In cold, alpine environments such as Banner Summit, there was often extreme temperature gradients in the top $25 \mathrm{~cm}$ that can lead to the formation of faceted snow. However, the diurnal nature of the upper $25 \mathrm{~cm}$ often means that critical temperature gradients are not sustained long enough to produce faceted snow forms. The below analysis focuses on the upper $25 \mathrm{~cm}$ because this is the extent of solar radiation penetration into the snowpack. 

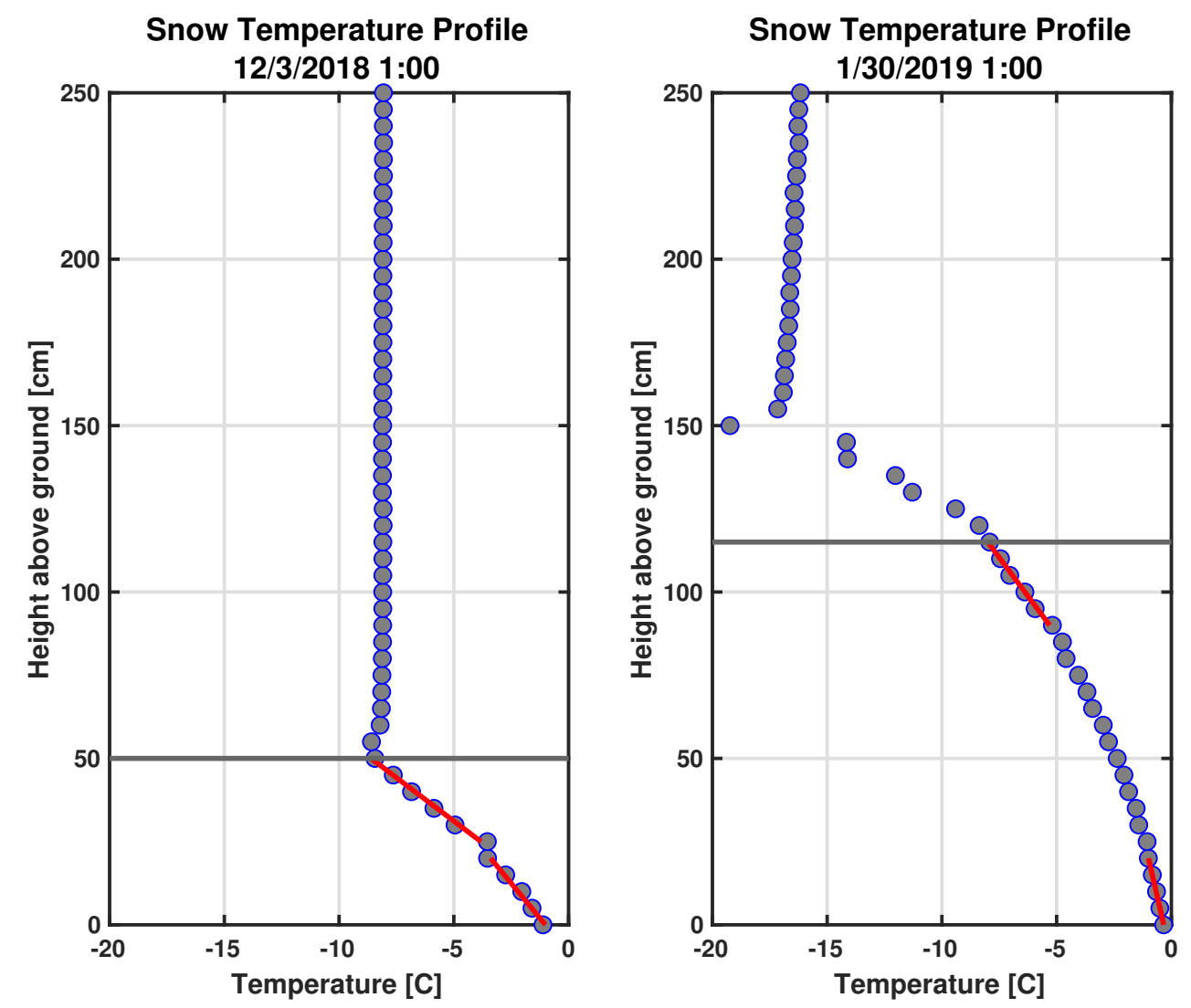

Figure 3.2: Examples of a first order regression fit to the upper $25 \mathrm{~cm}$ and lowest $20 \mathrm{~cm}$. The snow surface, as measured by the Banner Summit SNOTEL site is the horizontal, dark gray line which marks the upper limit (snow depth) of the upper $25 \mathrm{~cm}$ interval. The two figures are from two time periods during 2019 and illustrate differences between a shallow and a deeper snowpack. Snow accumulation on the temperature sensors is likely occurring between $120-145 \mathrm{~cm}$ in the figure on the right. 


\section{CHAPTER 4: RESULTS}

\subsection{Thermocouple Array}

The instrument was installed and fully operational on November 16, 2018 and collected continuous temperature measurements for the whole season. Some challenges from this winter included: (i) sagging of the support cables, (ii) snow bridging between vertical steel supports causing a deeper snow profile, (iii) snow depths exceeded the height of our uppermost sensor, (iv) some thermocouples are functioning intermittently after the major snowfall in February, and (iv) channelized/irregular melt patterns around the structure of the sensor in the spring. Despite the above challenges, this dataset suggests that it is possible to use this instrument as a tool for continuously measuring the temperature profile of a snowpack.

Throughout the season, as snow accumulates, the settling snowpack applies an increasing downward force on the sensor. As a result, some of the support cables sag a few centimeters. In 2020, springs were added to each cable to reduce the amount of sag; this was successful and greatly reduced error in the height of each measurement. The cables also act as a support for the snowpack, so as the snow settles, there is often an elevated snow surface at the temperature array. This promotes the growth of a snow bridge between the two vertical supports. This bridging effect is observable 
in this data when comparing the snow depth to the temperature profile.

Thermocouples buried in the soil and at the ground surface consistently read about $0^{\circ} \mathrm{C}$ (Figure 1.2). Moving up through the snowpack, there is a consistent temperature decrease from the $0^{\circ} \mathrm{C}$ ground measurement to air temperature (Figure 4.3). The array of thermocouples above the snowpack measure the same temperature and have much larger diurnal fluctuation than buried sensors (Figure 4.4). The snowpack has a large damping effect on temperature fluctuations which makes it possible to estimate snow depth using the temperature profile. However, the snow bridging is evident in this temperature damping and leads to overestimation of snow depth when using the temperature profile as a metric $(4.2-4.1)$.

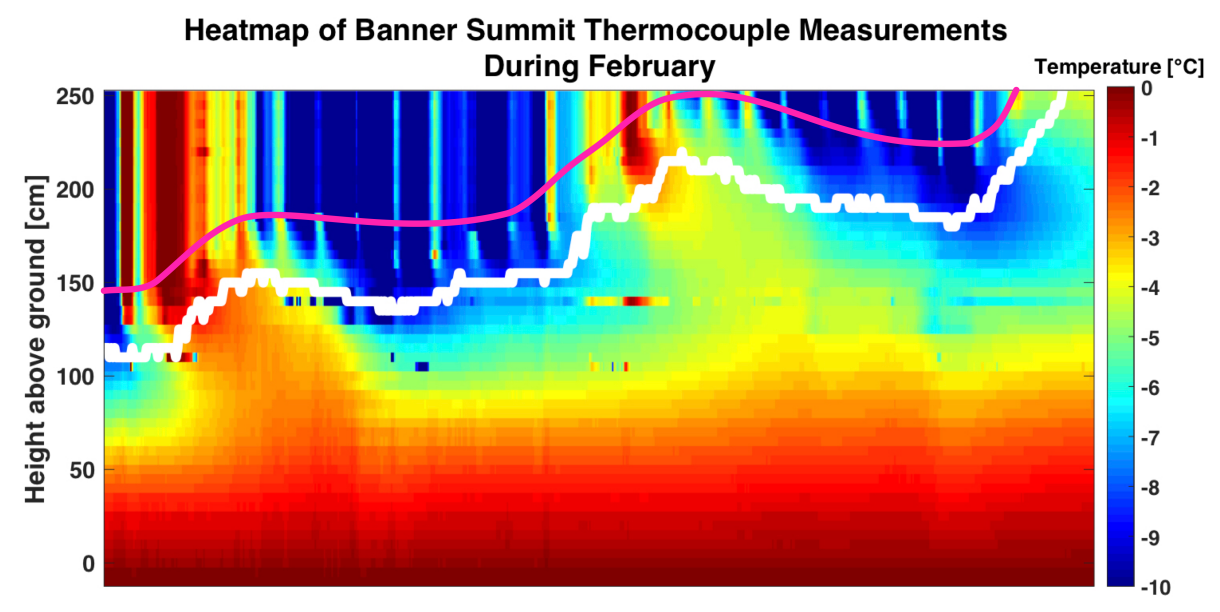

Figure 4.1: Plot of temperature profile in snowpack vs. time for the thermocouple array in the Banner Summit study area. The gradient in colors from red to blue designates a range in temperatures from 0 to $-10{ }^{\circ} \mathrm{C}$. The white line shows snow depth as measured by the adjacent SNOTEL instrument array. The pink line shows our inferred snow depth based on temperature differences between thermocouples (no temperature difference indicates that the sensors are above the snow surface). The pink line is consistently above the white line, indicating snow bridging. 


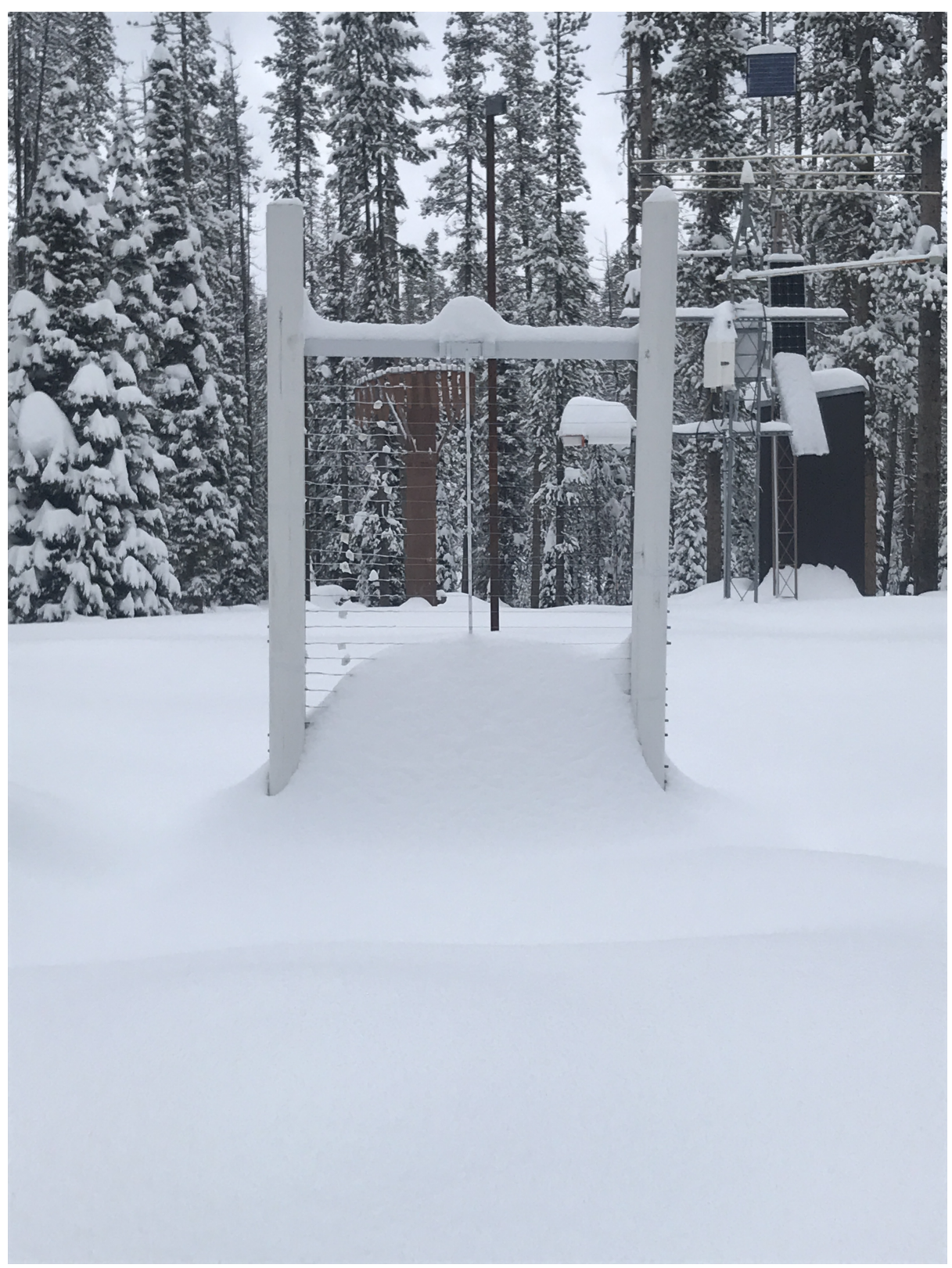

Figure 4.2: Photograph of instrument array on 01/18/19 showing major snow accumulation (bridging) between the two main support posts. 

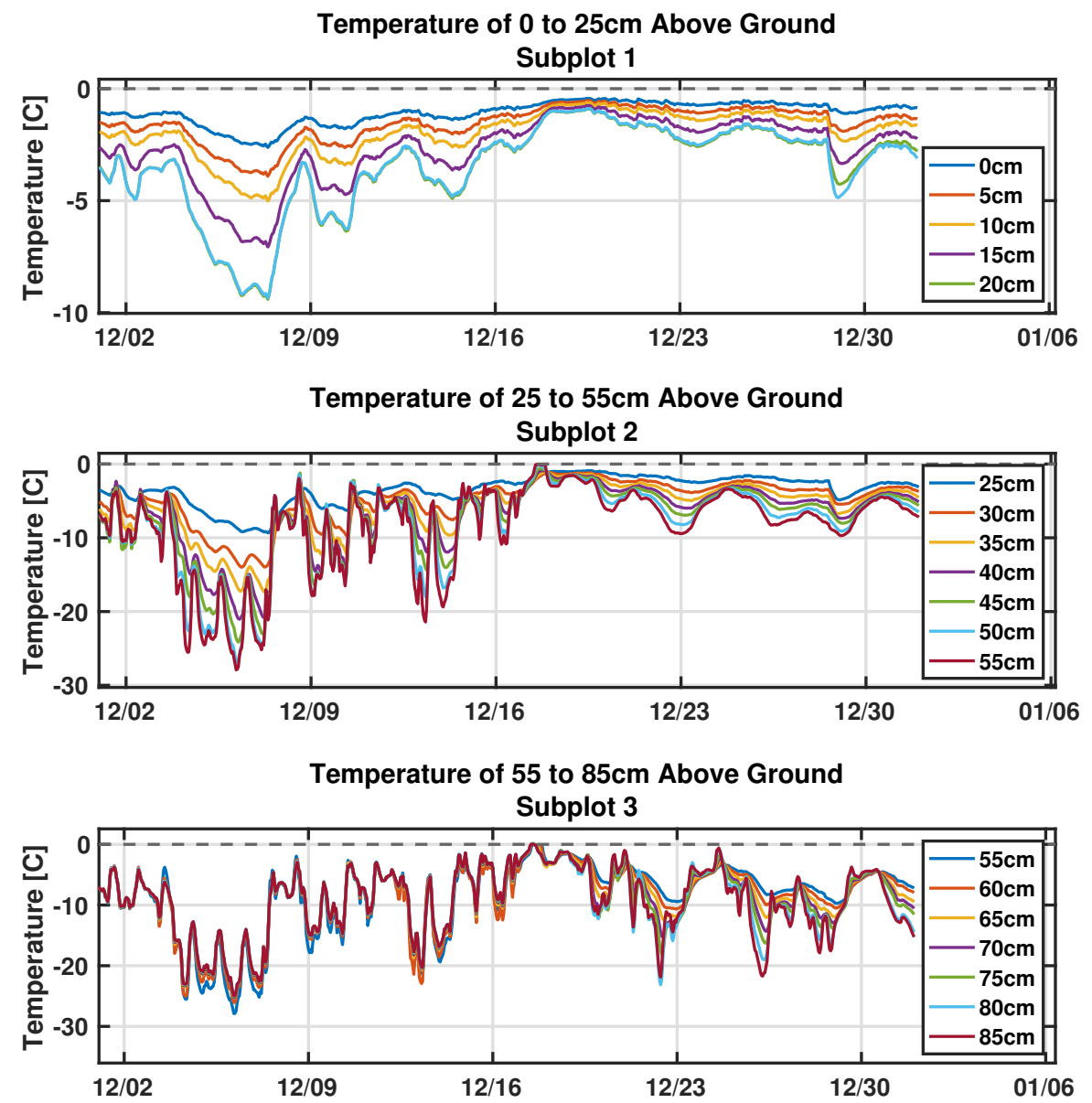

Figure 4.3: Subplot 1: Temperature measurement between 0cm up to $20 \mathrm{~cm}$ above ground. At this point, they are all buried in snow. Subplot 2: Temperature measurements for the thermocouples between $25 \mathrm{~cm}$ and $55 \mathrm{~cm}$ above ground. Subplot 3: Temperature measurements for the thermocouples between $55 \mathrm{~cm}$ and $85 \mathrm{~cm}$ above ground. At the begining of the time series, all thermocouples are above the snow surface and read a consistent temperature. Starting December 19th, there is snow accumulation that begins to bury these sensors and the become insulated from the strong diurnal temperature swings. 


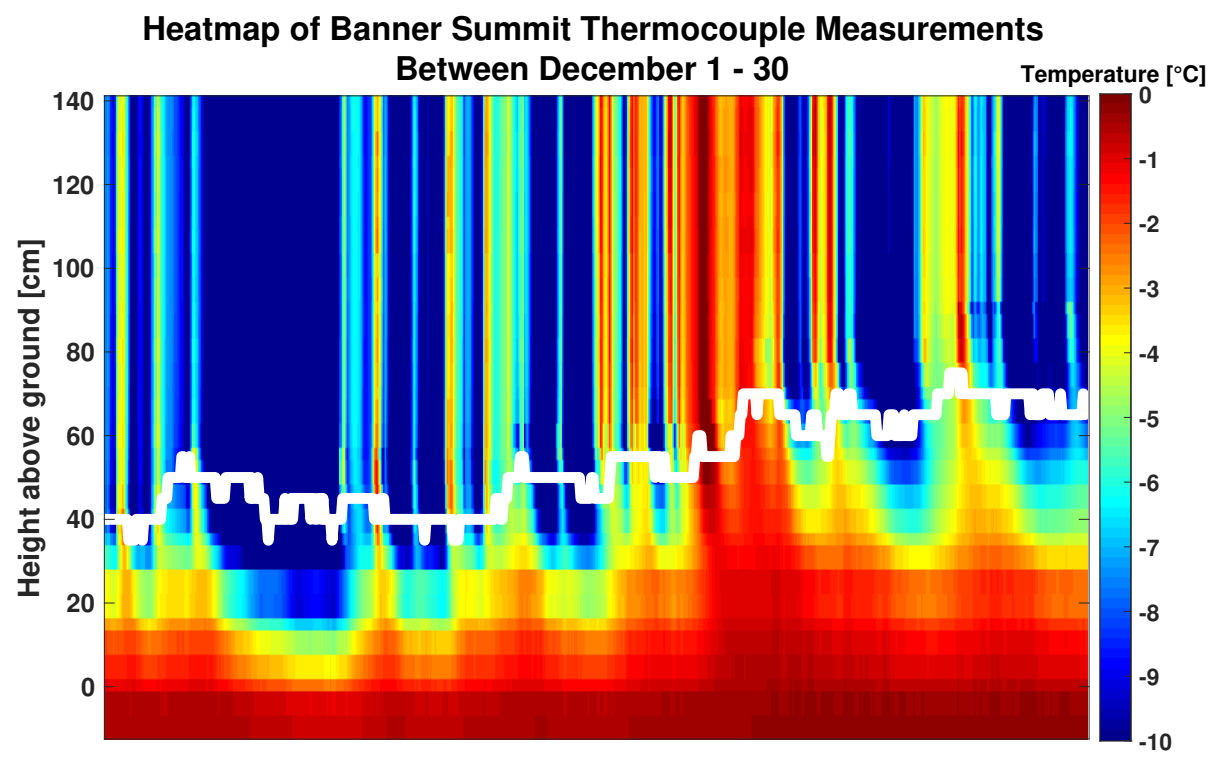

Figure 4.4: Continuous plot of the temperature measurements between December 1 - 30. The white line is snow depth recorded by an acoustic sensor at the nearby SNOTEL site.

The precision and accuracy of this instrument is tested during isothermal conditions in the snowpack. During water year 2019, the snowpack went isothermal around March 31 (Figure 5.1). Following warm storm events in early April that deposited a few inches of snow, peak snowmelt started on April 16. This followed a couple warm storm events that deposited a few inches of snow in early April (Figure 4.7). The instrument has an uncertainty $\pm 0.06{ }^{\circ} \mathrm{C}$ which is the standard deviation of all the thermocouple measurements during the isothermal snowpack (Figures $4.5-4.6$ ). As seen in Figure 4.5, thermocouples show heterogeneity in recorded temperature. One possible explanation for this is the aged Campbell Scientific AM32 Multiplexors that are used in the 2019 water year. These were later replaced because they failed during the 2019 summer. 


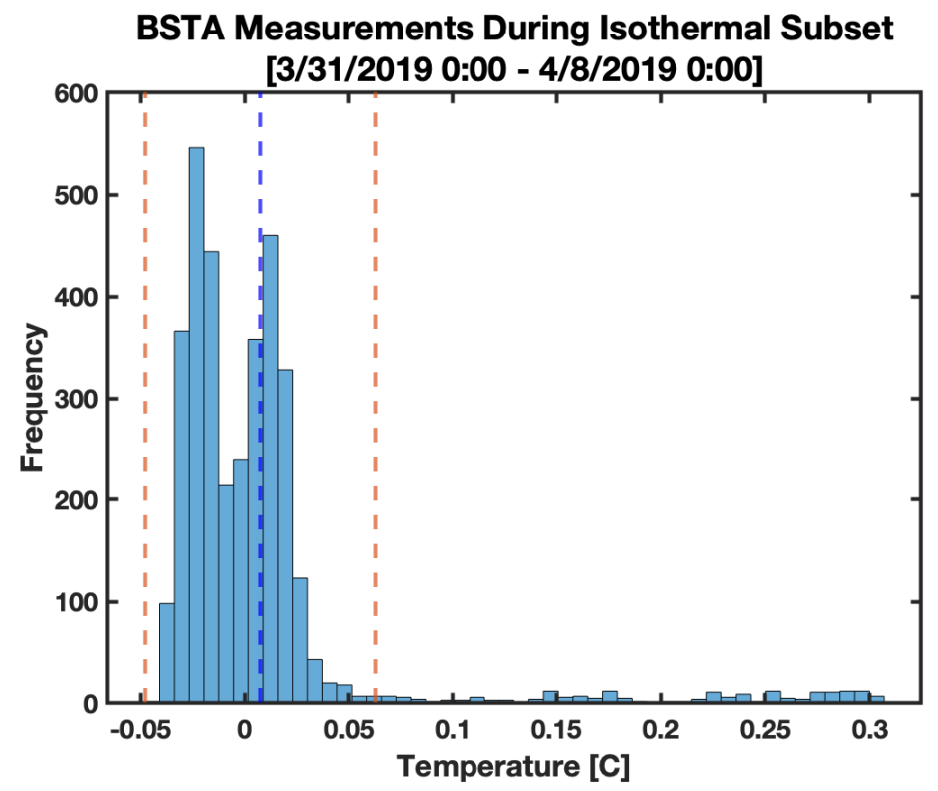

Figure 4.6: Histogram of the temperature measurements taken during an isothermal snowpack in 2019 which shows a standard deviation of \pm 0.06 ${ }^{\circ} \mathrm{C}$.

In the beginning of April, each buried thermocouple showed very little daily temperature fluctuations (Figure 4.8). Directly after peak snowmelt started, the daily range for each thermocouple increased greatly and in some cases is larger than $1^{\circ} \mathrm{C}$. This increase in temperature fluctuation is likely caused by preferential flow of snowmelt due to the instrument. During the melt season, a channel formed between the two vertical supports creating a depression in the snow surface where the thermocouples are placed. Because the instrument has different thermal properties (e.g. albedo and thermal conductivity), it affects melt rates and characteristics of the snow it is in contact with. It is suspected that the instrument facilitates an increased downward flow of water which creates air pockets around the sensor that affect its ability to accurately measure snow temperature in the spring. 


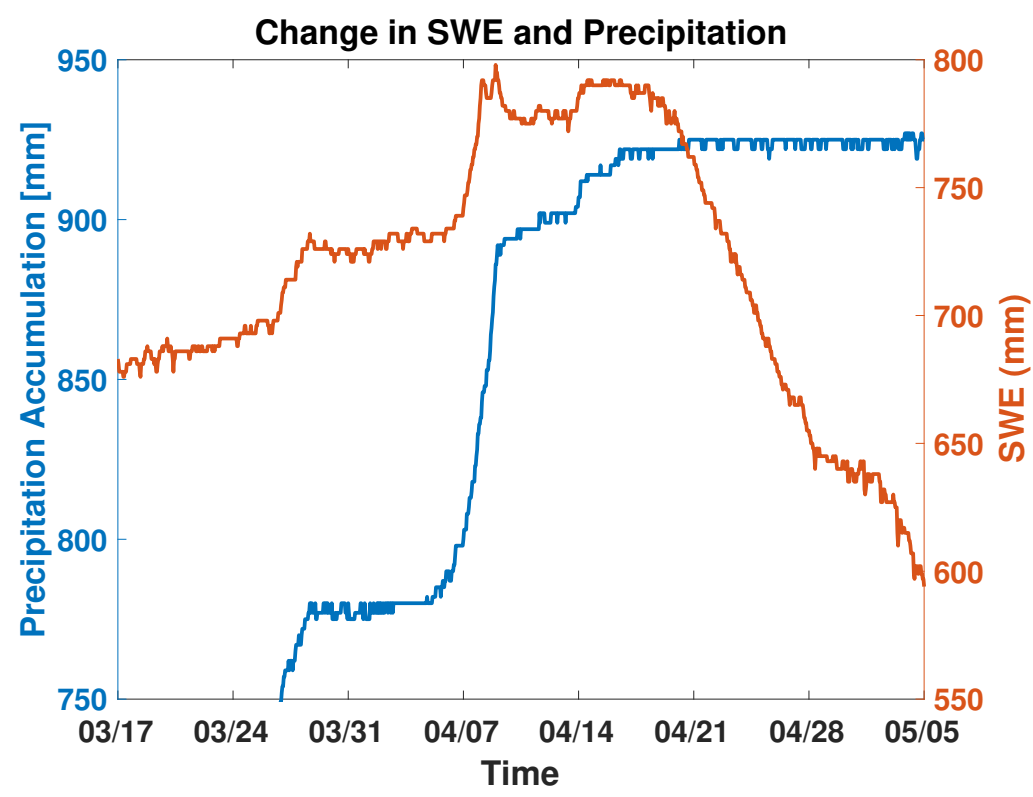

Figure 4.7: Time series of SWE at Banner summit plotted with the precipitation at the Banner Summit SNOTEL site. 


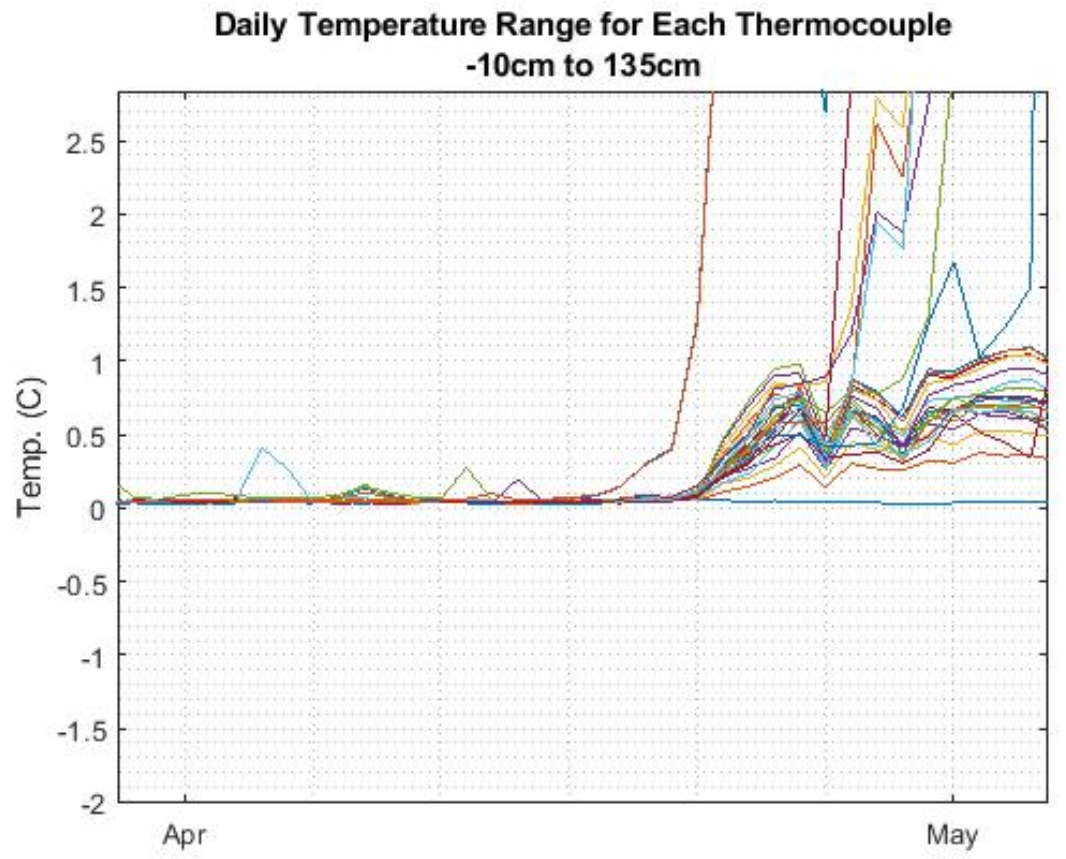

Figure 4.8: The daily temperature range for each thermocouple between $-10 \mathrm{~cm}$ to $135 \mathrm{~cm}$ showing the increase in temperature range directly following major snowmelt.

\subsection{Temperature Gradient Analysis}

Avalanche forecasters are primarily interested in the timing and duration of critical temperature gradients in the snowpack. Figure 4.9 shows temperature gradients in the lowest $20 \mathrm{~cm}$ throughout the whole period of record. These results suggest that higher than critical temperature gradients persist throughout December 2019, but not subsequently. Figure 4.9 shows temperature gradients in the upper $25 \mathrm{~cm}$ during the whole period of record. These results illustrate the high amount of variability in the upper layers of the snowpack. Unlike temperature gradients in the lowest $20 \mathrm{~cm}$, the top $25 \mathrm{~cm}$ continually changes because it is not insulated from the atmosphere. For the whole season, the upper layers continually fluctuate between the two significant 
types of snow metamorphism; equilibrium and kinetic (Figure 4.9). The continuous temperature record provided by the BSTA provides insight to the duration and nature of the temperature profile in the upper $25 \mathrm{~cm}$ as it fluctuates diurnally. Analysis will now be split into three specific periods: December, February, and late March, as presented in histograms.

December, 2019: In both the upper $25 \mathrm{~cm}$ (Figure 4.10) and lower $20 \mathrm{~cm}$ (Figure 4.12), temperature gradients show a long tail towards negative values, and $50 \%$ of measurements fall within the above-critical range. Cold air temperatures, coupled with a shallow snowpack during December forced above-critical temperature gradients on the snowpack for most of the month.

February, 2019: The upper $25 \mathrm{~cm}$ (Figure 4.13) shows a reduced range of temperature gradients, such that only $12 \%$ of measurements fall within the above-critical range. The lower $20 \mathrm{~cm}$ (Figure 4.14 ) has become nearly isothermal, so that gradients show a very narrow range that cluster slightly below $0^{\circ} \mathrm{C}$. By this point in the season, the lowest $20 \mathrm{~cm}$ of the snowpack is well insulated; thus, there is little to no temperature gradient. Although the upper portion of the snowpack experiences substantial temperature gradients, they are not persistent because of the diurnal solar cycle.

Late March, 2019: Warmer air temperatures during March prevented large temperature gradients in the upper $25 \mathrm{~cm}$ (Figure 4.15). Much like the Feburary subset, the lowest $20 \mathrm{~cm}$ are very insulated and are nearly isothermal at $0{ }^{\circ} \mathrm{C}$ (Figure 4.16 ). This subset displays the snowpack as it progresses towards isothermal conditions.

In addition to the figures shown here, time-lapse movies (see link in appendix) are a helpful way to visualize how temperature gradients change over time. These movies highlight the depth of diurnal solar radiation input and help provide context 
that aids in the understanding of these processes.
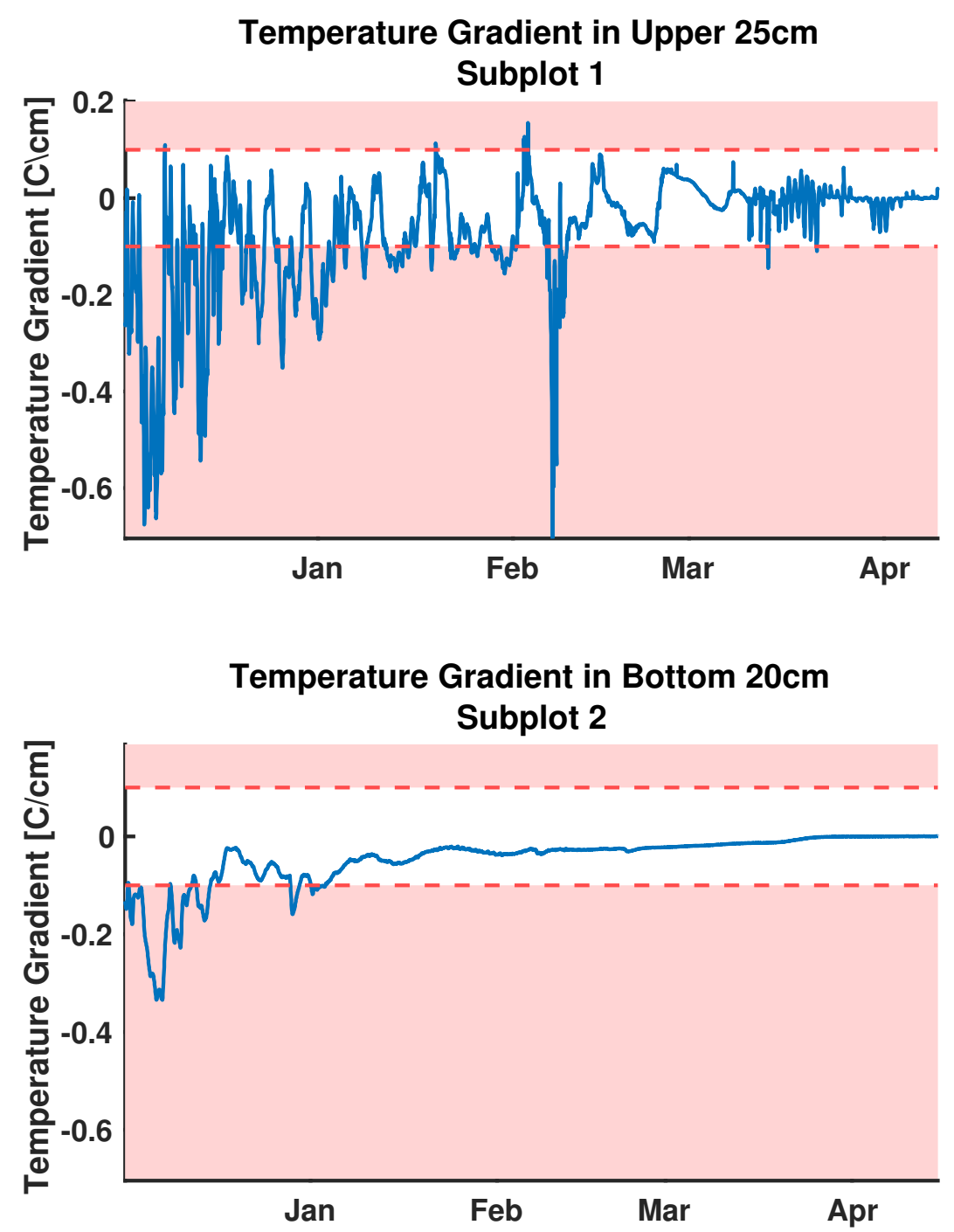

Figure 4.9: Subplot 1: Temperature gradient in top 25cm of snowpack during 2019 period of record. Gradients in the shaded red area are considered greater than critical and destructive metamorphism is likely to occur. Subplot 2: Temperature gradient in lowest $20 \mathrm{~cm}$ of snowpack during 2019 period of record. 


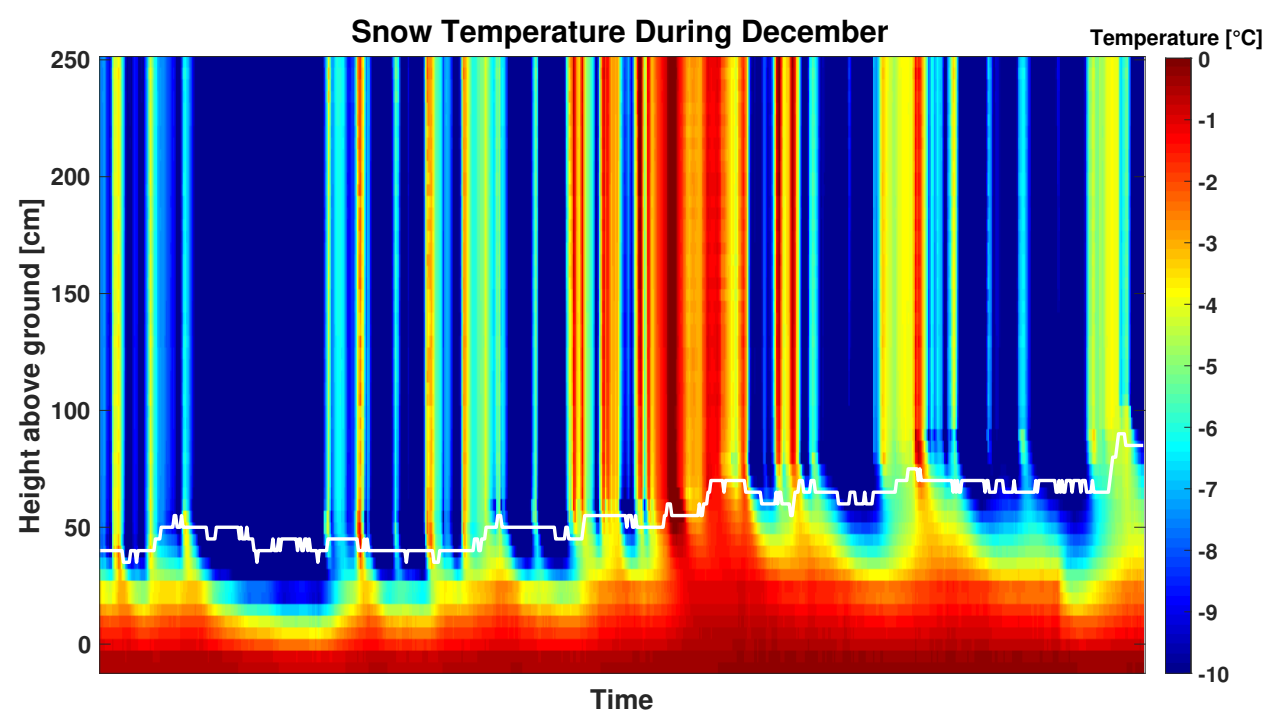

Figure 4.10: Heatmap of data collected by BSTA during December. The solid white line indicates snow depth measured by the Banner Summit SNOTEL site.

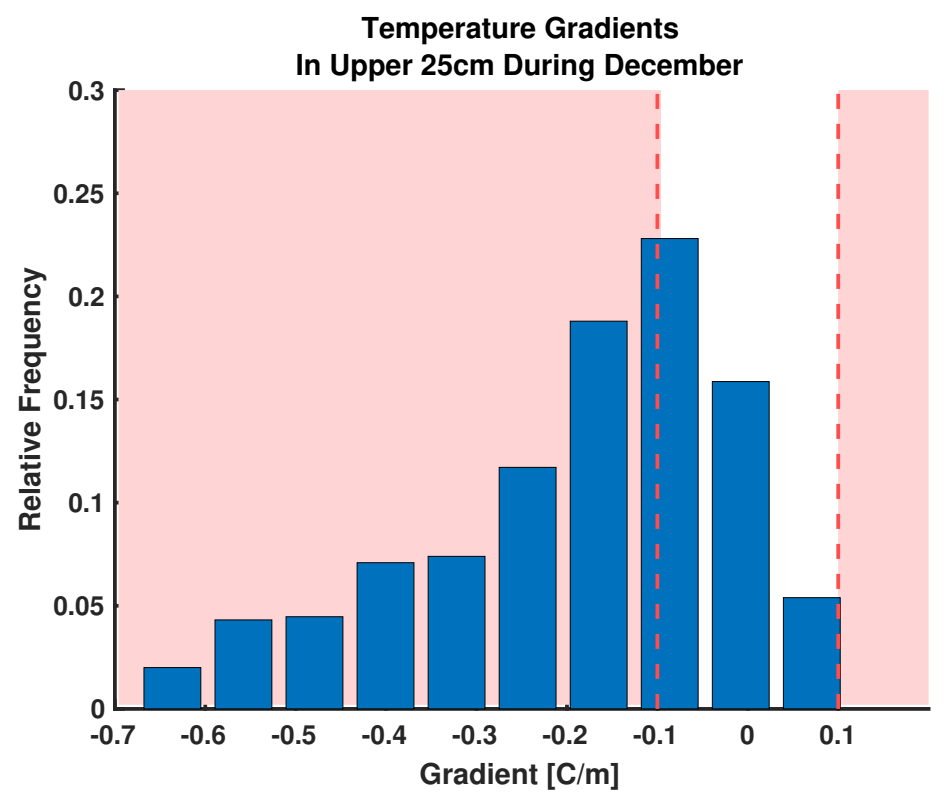

Figure 4.11: Relative density histogram of temperature gradients in the upper $25 \mathrm{~cm}$ of the snowpack during December. Gradients in the shaded red area are considered greater than critical and are facet forming. 


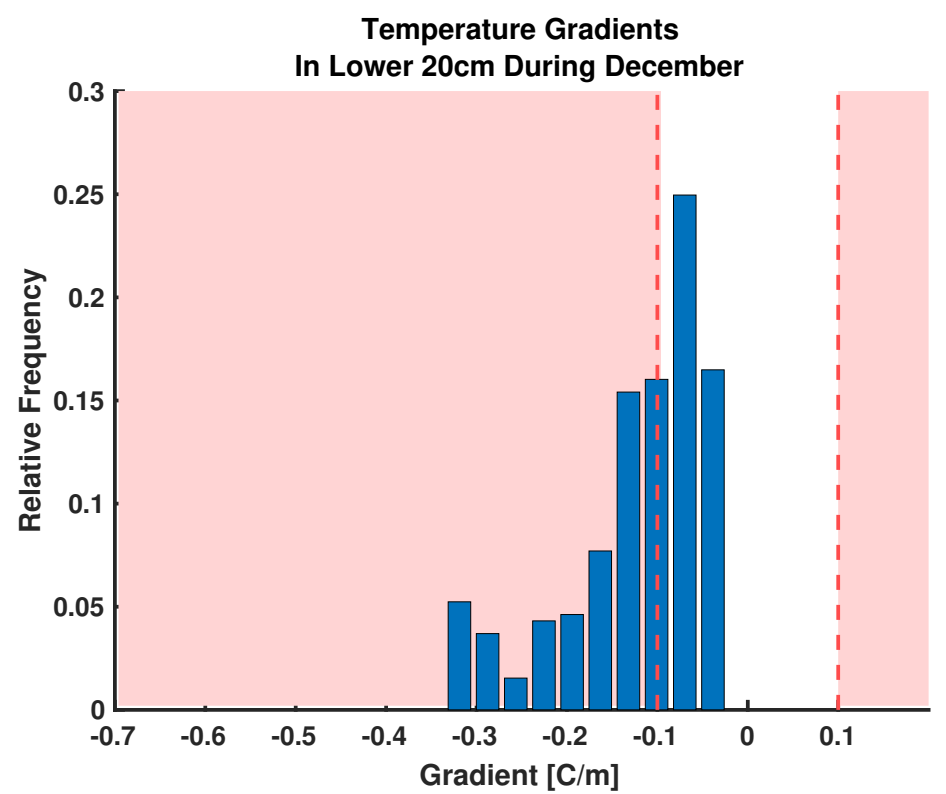

Figure 4.12: Relative density histogram of temperature gradients in the lowest $20 \mathrm{~cm}$ of the snowpack during December.

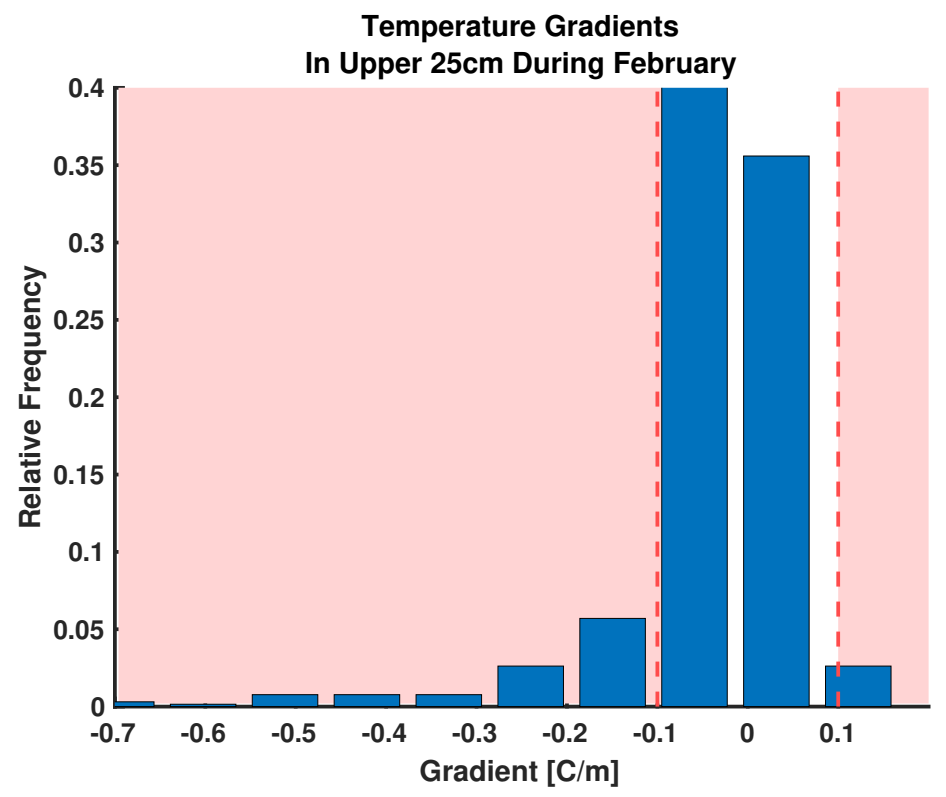

Figure 4.13: Relative density histogram of temperature gradients in the upper $25 \mathrm{~cm}$ of the snowpack during February. 


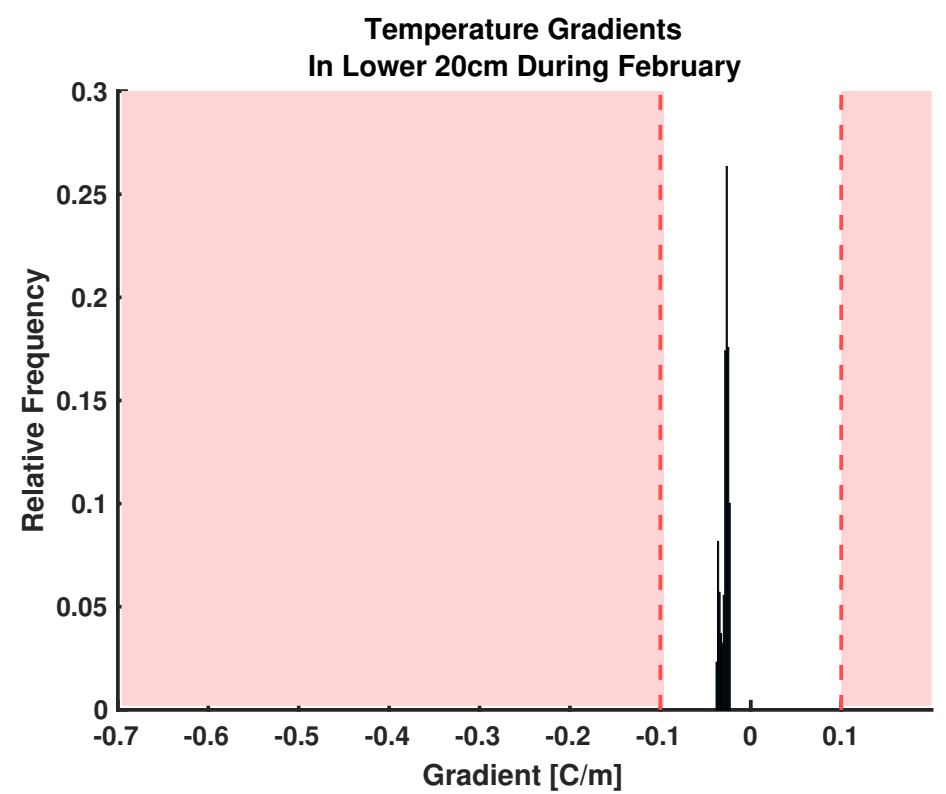

Figure 4.14: Relative density histogram of temperature gradients in the lowest $20 \mathrm{~cm}$ of the snowpack during February.

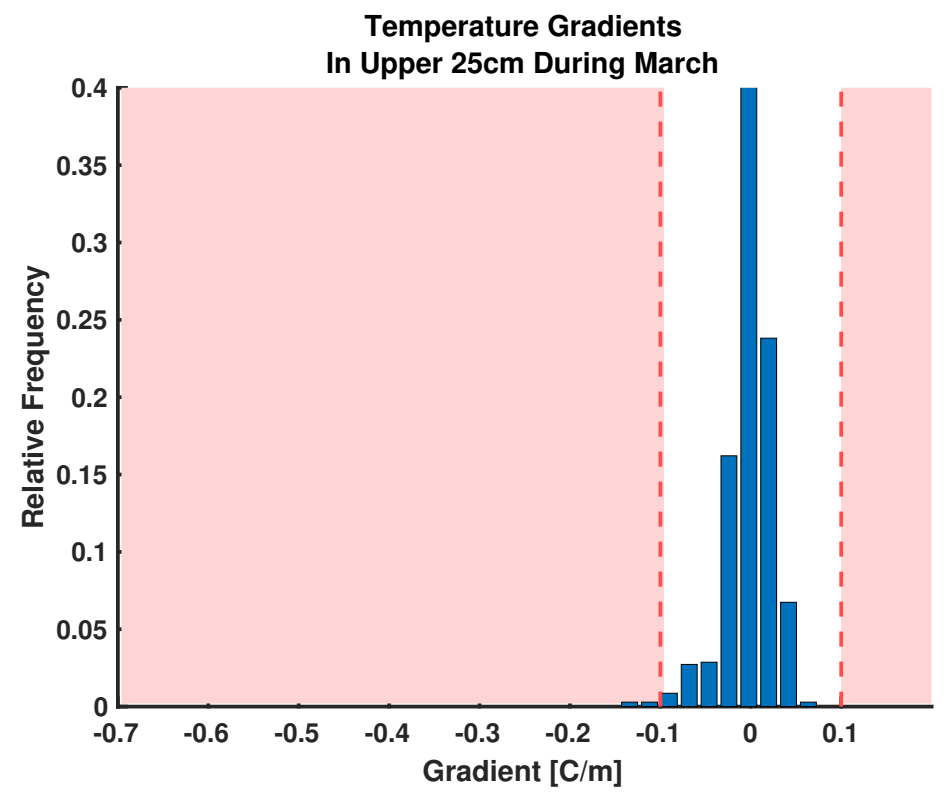

Figure 4.15: Relative density histogram of temperature gradients in the upper $25 \mathrm{~cm}$ of the snowpack during March. 


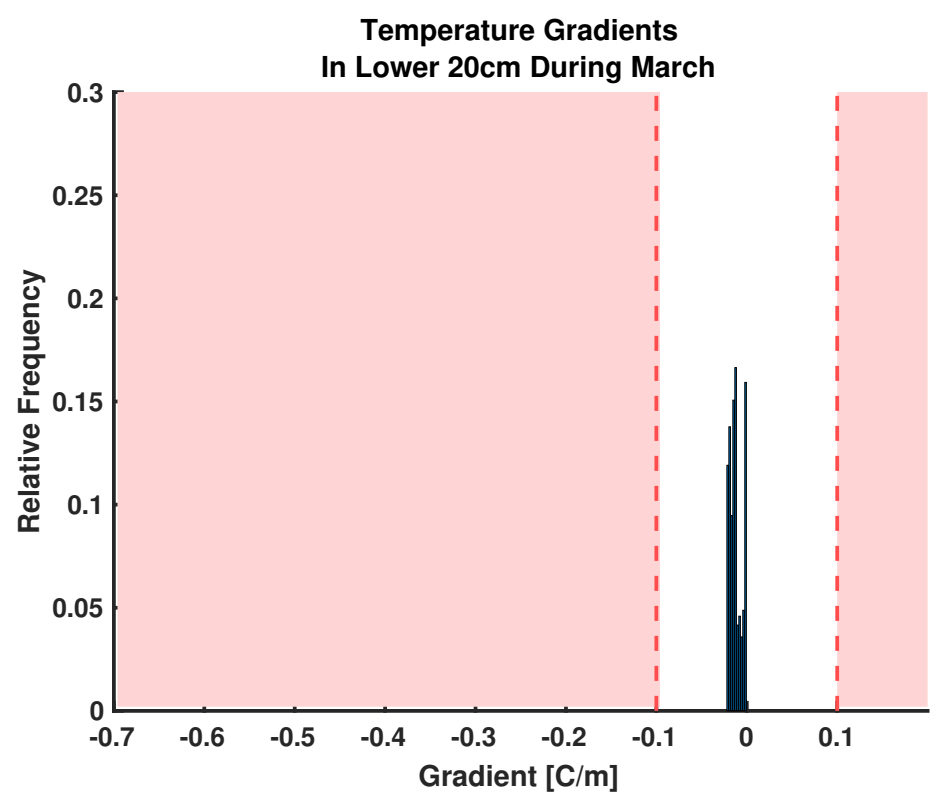

Figure 4.16: Relative density histogram of temperature gradients in the lowest $20 \mathrm{~cm}$ of the snowpack during March.

The uncertainty of this temperature gradient analysis is calculated in MATLAB using a Monte-Carlo Simulation. First, the built in MATLAB function 'randn' is used to produce normally distributed, randomly generated data with a mean of one. This data is then multiplied by the standard deviation of thermocouple measurements during the isothermal snowpack to create a synthetic error distribution with mean of zero and standard deviation of $\pm 0.06{ }^{\circ} \mathrm{C}$. This error is added to the first order polynomial best fit for a given temperature gradient, then this whole process is repeated 1,000 times to create normally distributed, synthetic temperature gradient measurements. Results are shown in Figure 4.17. The uncertainty in the sensor location, due to sagging of the wires, would also impact the temperature gradient estimates. Including this effect will be the subject of future work. 


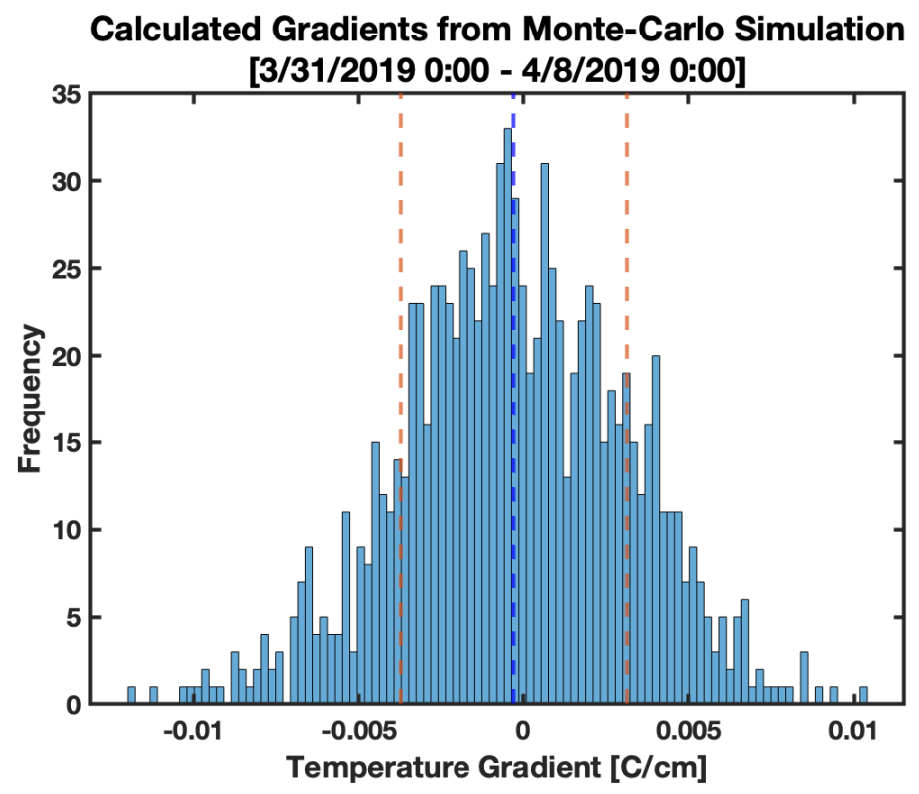

Figure 4.17: Results of the Monte-Carlo Simulation of temperature gradi-ent analysis based on $\pm 0.06{ }^{\circ} \mathrm{C}$ error on thermocouple measurements. 


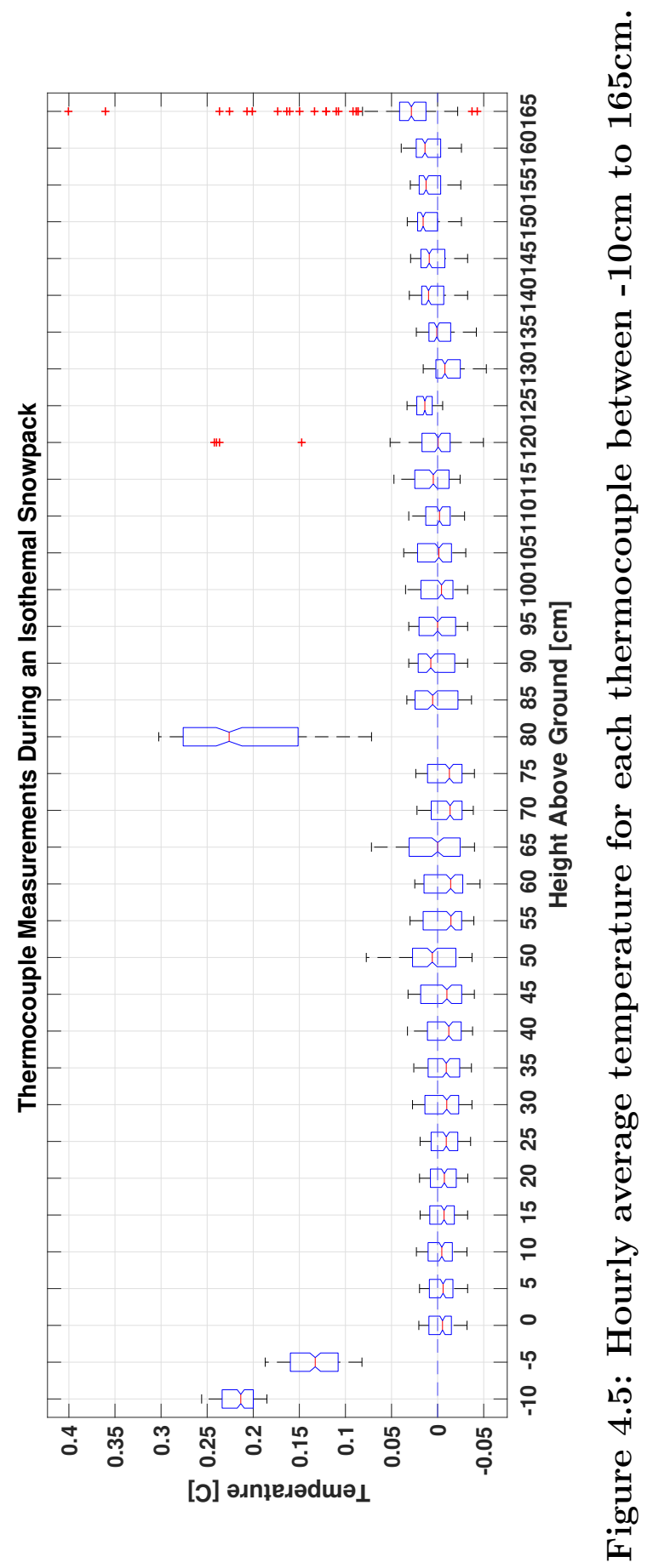




\section{CHAPTER 5:}

\section{DISCUSSION}

\subsection{Temperature Gradient Analysis}

In December of 2019, the lowest $20 \mathrm{~cm}$ formed depth hoar and had above critical temperature gradients for around $50 \%$ of the month. Critical temperature gradients were no longer present in the lower $20 \mathrm{~cm}$ after the beginning of January. Comparatively, critical temperature gradients in the upper $25 \mathrm{~cm}$ are present throughout the season and can have a much larger magnitude, but the duration relies primarily on the diurnal solar cycle. Snow bridging on our sensor increases the uncertainty in upper gradient calculations and more work needs to focus on preventing this snow buildup. Although this bridging effect influences data in the upper portion of the snowpack, there is a minimal affect on lower temperature measurements. Although snowpack conditions can vary widely at the basin scale, the BSTA permits the construction of statistical relationships between a single site and nearby features such as avalanche starting zones.

Kinetic metamorphism is the process of vapor transport along a thermal gradient (Sommerfeld and LaChapelle, 1970). As long as the gradient is maintained, as is usually the case in cold environments, the process continually acts on the snowpack. The snow characteristics during the beginning of this process have a strong effect on 
its progress (Sommerfeld and LaChapelle, 1970). In new, fine grained, porous snow, there are more grains in which the diffusing vapor can freeze. Consequently, the grains do not grow very large, and hollow pyramids are not common (Sommerfeld and LaChapelle, 1970). If temperature-gradient metamorphism starts in larger-grained, equi-temprature metamorphosed snow, there are fewer crystals on which the vapor can freeze. Under a consistent thermal gradient, these crystals will grow larger, and hollow pyramids along with lattice grains may be found (Akitaya, 1967).

Many different factors affect the rate and nature of temperature-gradient metamorphism, and a continual collection of the snowpack temperature data is critical in understanding these processes. Further work should focus on collecting more frequent snow pit observations to document the rate of change in the snow's microstructure.

\subsection{Isothermal Snowpack and Runoff Timing}

To generate considerable snowmelt runoff, a snowpack must experience three basic phases - warming, ripening, and output. In an idealized scenario, warming and heat transfer increase the temperature of the entire snowpack to $0{ }^{\circ} \mathrm{C}$. At the point where it becomes isothermal, it enters the ripening phase, where any additional absorbed energy causes snow melt. Although absorbed energy melts snow, the majority of melt water is retained in the snowpack via surface tension and continuous pores filled with air, until the snowpack reaches the liquid water holding capacity ( 2-5\%) (Dingman, 2015). After the snowpack reaches its liquid water holding capacity, it enters the output phase where further absorption of energy produces water output. It is important to note that this is a very idealized sequence. For example, melting often occurs at the surface before the snowpack becomes isothermal and may percolate deeper into the snowpack where it can refreeze and form ice layers. The percolation is also 
heterogeneous. Vertical pipes typically form that route water vertically, until larger changes in hydraulic conductivity cause pooling or lateral flow at layer boundaries (Evans et al., 2016; Eiriksson et al., 2013). In addition, latent heat exchange during these phase changes contributes significantly to the overall snowpack energy balance and internal processes.

The SNOTEL network is currently the most robust system for measuring snowpack characteristics and it creates hourly reports of snow depth, snow water equivelence (SWE), and precipitation across the Western United States. Using snow depth and SWE to calculate snow density, it is possible to estimate when a snowpack has reached ripe conditions. This usually occurs around $400 \mathrm{~kg} \mathrm{~m}^{-3}$ or $40 \%$ density, although this is site dependent and depends on the maximum dry snow density. The current network lacks the ability to measure snowpack temperatures. Therefore it is very hard to predict the beginning of the ripening phase. In a scenario with a lower density snowpack at the beginning of its ripening phase, there are few in situ measurements that provide the data necessary to make predictions on when the snowpack will enter the output phase. Combining data from the SNOTEL network, weather forecasts, and snowpack temperature arrays could provide a means to estimate the timing of the output phase. Below are fundamental equations that could be used to approach this problem.

From empirical studies, the maximum volumetric water content $\left(\theta_{\text {ret }}\right)$ that a snowpack can retain against gravity is defined as:

$$
\theta_{\text {ret }}=-0.0745 \frac{\rho_{\mathrm{s}}}{\rho_{\mathrm{w}}}+0.00267{\frac{\rho_{\mathrm{s}}^{2}}{\rho_{\mathrm{w}}}}^{2}
$$

Where $\rho_{\mathrm{s}}$ and $\rho_{\mathrm{w}}$ are the densities of snow and water respectively. Ripe snowpacks 
usually have a bulk density of $\rho_{s}=400 \mathrm{~kg} \mathrm{~m}^{-3}$ and according to the above equation, this leads to a maximum volumetric water content of $\theta_{\text {ret }}=0.03$. The net energy $\left(\mathrm{Q}_{\mathrm{m} 2}\right)$ in $\mathrm{J} \mathrm{m}^{-2}$ required to complete the ripening phase is defined as:

$$
Q_{m 2}=\theta_{\text {ret }} * h_{s} * \rho_{w} * \lambda_{f}
$$

Where $\mathrm{h}_{\mathrm{s}}$ is snow depth and $\lambda_{f}$ is the latent heat of fusion $\left(0.334 \mathrm{MJ} \mathrm{kg}^{-1}\right)$.

Using parameters such as weather forecasts, snow albedo, the temperature profile, etc., it is possible to estimate the potential net energy exchange between the snowpack and atmosphere. If there is a net energy exchange into the snow that exceeds $\mathrm{Q}_{\mathrm{m} 2}$, the snowpack will likely enter the output phase.

Figures 5.1 - 5.2 show snowpack temperature measurements as it reaches isothermal conditions at Banner Summit. Although the beginning of the ripening phase is defined as isothermal conditions at $0^{\circ} \mathrm{C}$, this study interprets isothermal conditions when the range of temperature measurements on the BSTA drops below the estimated accuracy of the temperature probes. The instrument's accuracy dictates this interpretation because, although it's minimal, there is an inherent error in temperature measurements. The minimum temperature range in 2019 is $0.02 \mathrm{C}$ and occurs on March 31st. This marks the beginning of the ripening phase.

The ability to precisely measure when the snowpack goes isothermal provides context when observing the following melt stages. Figure 5.3 shows snow density and snow water equivalent with an overlay of the interpreted melt stages. Although the snowpack becomes isothermal on March 31st, the liquid water capacity (LWC) is below the max capacity of the snowpack. Between the 31st - April 6th, air temperatures were below freezing, and storms brought fresh snow. During April 7th - 9th, there 


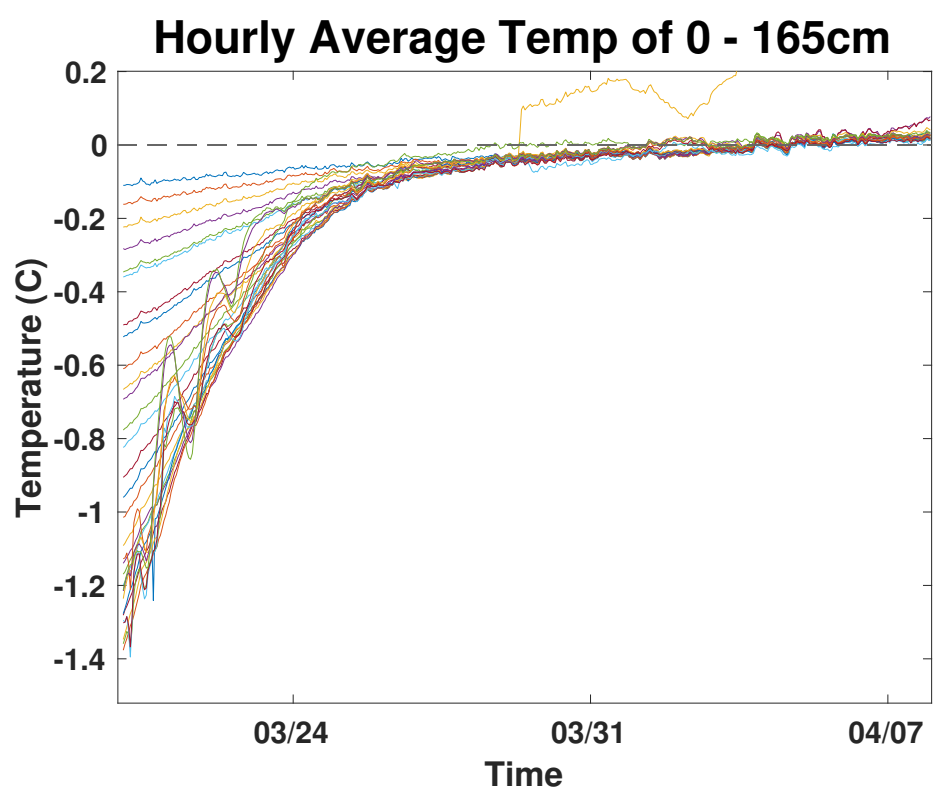

Figure 5.1: Progression of snowpack temperatures leading to isothermal conditions starting March 31.

was rain on snow that increased snow density to $\sim 40 \%$. Between April 9 - 10, the snowpack lost $\sim 2 \mathrm{~cm}$ of SWE, marking the beginning of the output phase.

Using these interpretations at Banner Summit to predict runoff at the basin scale poses several challenges. Perhaps most significantly, measurements at a single point don't characterize the behavior of an entire basin. To establish any relationship between these measurements and nearby streamflow, a more extended period of record is necessary. However, this dataset provides more context when interpreting springtime runoff at a nearby stream gauge. Figure 5.4 is a hydrograph from the nearby stream gauge with an overlay of the interpreted melt stages at Banner Summit. Shortly after the snowpack reaches the ripening phase on March 31st, streamflow at this gauge departs from normal conditions and is above the median. Additionally, when our study site reaches its output phase, there is a significant increase in streamflow. 


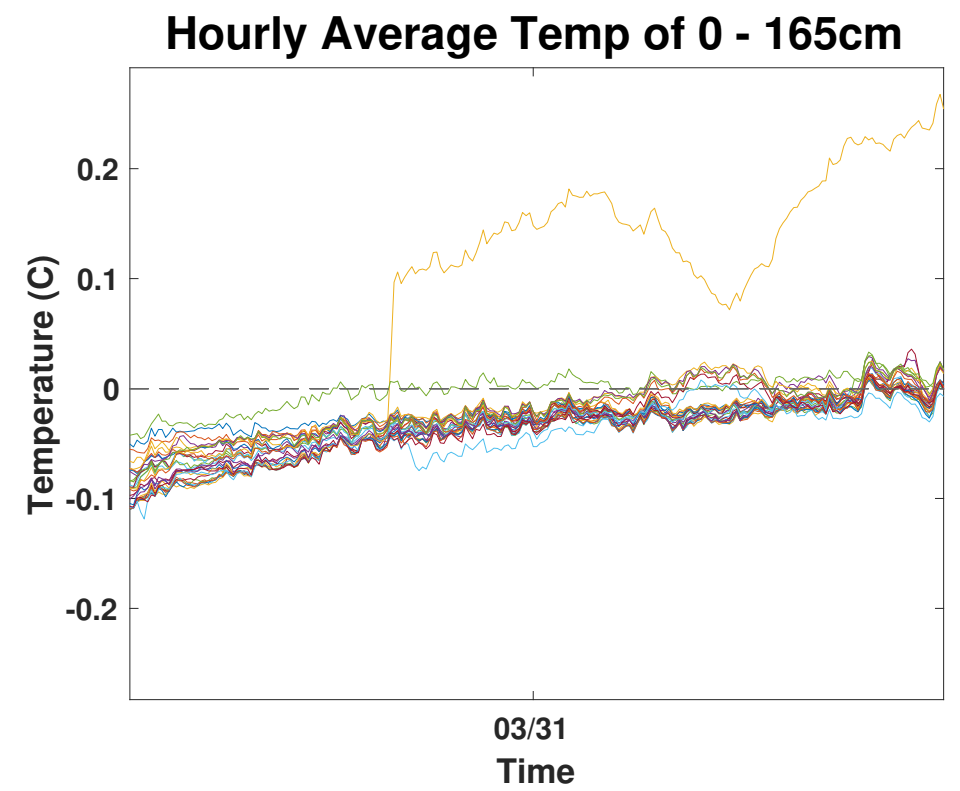

Figure 5.2: A zoomed-in sub-plot of data shown in Figure 5.1. This figure shows March 30 - 31 and the smallest range of thermocouple measurements which occurs on March 31. 


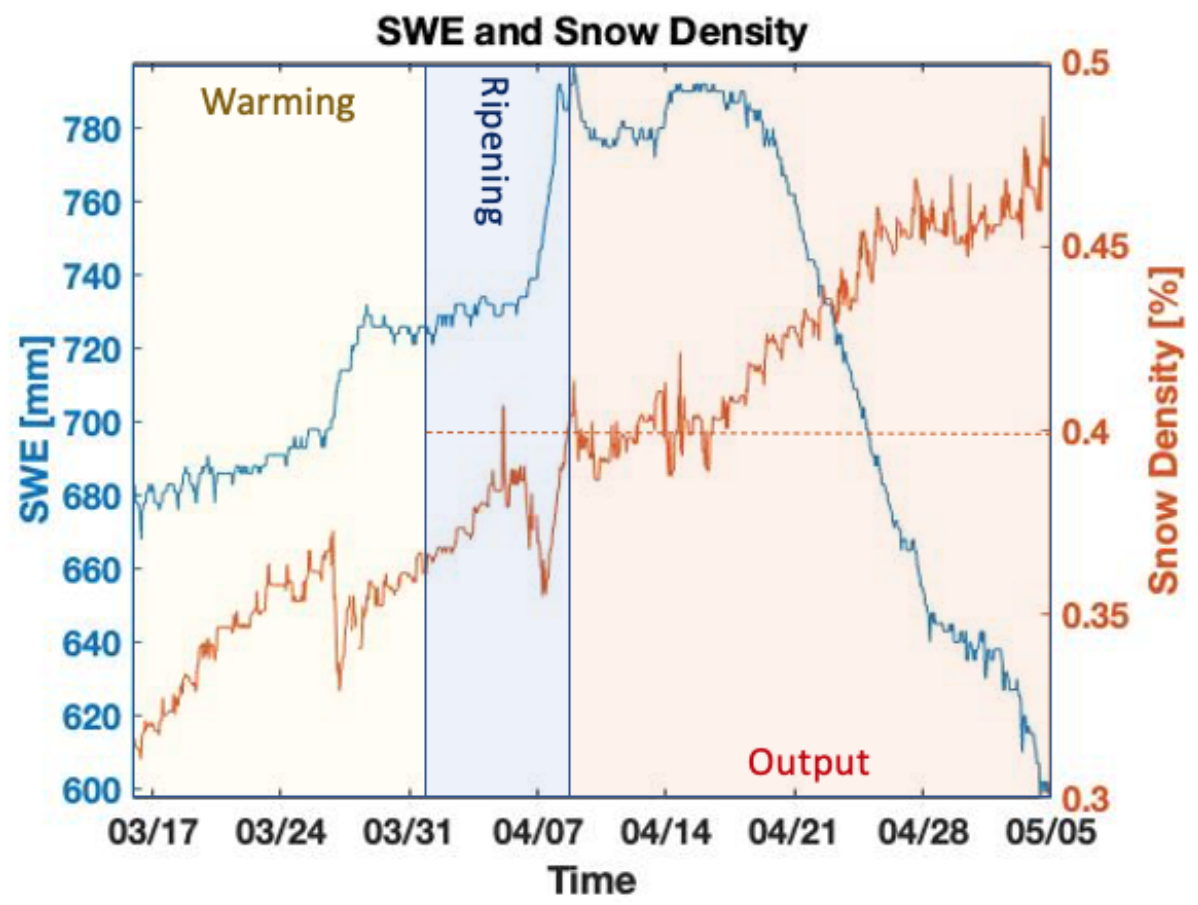

Figure 5.3: SWE and Snow Density during the warming, ripening, and output phases at Banner Summit. This figre Shows that significant loss in SWE occured after the snowpack reached $\sim 40 \%$ density. 
USGS 13295000 VALLEY CREEK AT STANLEY ID

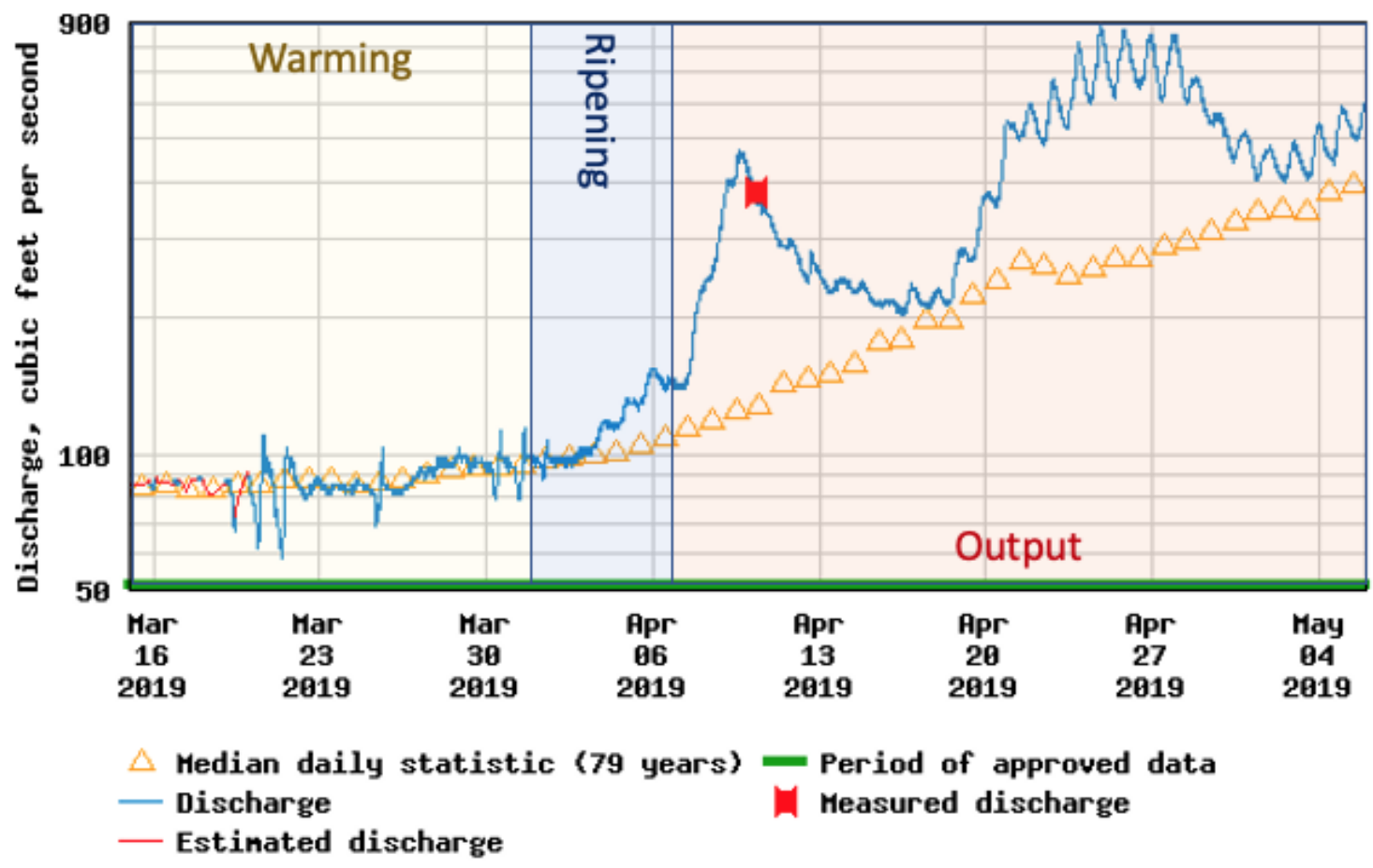

Figure 5.4: Unregulated streamflow data from a USGS stream gauge near Banner Summit. This figure shows how the observed streamflow departs from normal conditions shortly after the snowpack at our study site goes isothermal. 


\section{CHAPTER 6:}

\section{CONCLUSION}

The Banner Summit Thermocouple Array is successful at measuring the temperature profile of a snowpack with an accuracy of $\pm 0.06{ }^{\circ} \mathrm{C}$ (Figure 4.6). Critical temperature gradients were no longer present in the lower $20 \mathrm{~cm}$ after the beginning of January. This continuous temperature data allows us to conduct further analysis on the magnitude and duration of critical temperature gradients with an uncertainty of \pm 0.003 ${ }^{\circ} \mathrm{C} / \mathrm{cm}$ (Figure 4.17). In December of 2019, the lowest $20 \mathrm{~cm}$ formed depth hoar and had above critical temperature gradients for around $50 \%$ of the month. Critical temperature gradients were no longer present in the lower $20 \mathrm{~cm}$ after the beginning of January. Temperature gradients in the upper $25 \mathrm{~cm}$ can have a much larger magnitude, but the duration is controlled primarily by the diurnal solar cycle. Because this instrument precisely measures isothermal conditions in a snowpack, it may be possible to improve predictions of major snowmelt. Although snowpack conditions can vary widely at the basin scale, the BSTA permits the construction of statistical relationships between a single site and nearby features such as stream gauges, or avalanche starting zones. A continuous snowpack temperature record, as derived via a temperature sensor array (as described here), will allow statistical analysis on avalanche hazards and snowmelt runoff. Further comparison between our results and snowpack energy balance models may provide insight into processes such as latent 
heat exchange and will help further our understanding of internal snowpack processes. 


\section{REFERENCES}

Akitaya, E. (1967). Some experiments on the growth of depth hoar. Physics of Snow and Ice, 1(2):713-723.

Akitaya, E. (1974). Studies on depth hoar. Contributions from the Institute of Low Temperature Science, 26:1-67.

Arenson, L. U., Colgan, W., and Marshall, H. P. (2015). Physical, thermal, and mechanical properties of snow, ice, and permafrost. In Snow and Ice-Related Hazards, Risks and Disasters, pages 35-75. Elsevier.

Barbolini, M., Baudone, M., Ferro, F., Ricchetti, L., and Stefanini, F. (2013). Nivexc: an electronic snow-pole for real-time monitoring of avalanche starting zones.

Beria, H., Larsen, J. R., Ceperley, N. C., Michelon, A., Vennemann, T., and Schaefli, B. (2018). Understanding snow hydrological processes through the lens of stable water isotopes. Wiley Interdisciplinary Reviews: Water, 5(6):e1311.

Colbeck, S. (1983). Theory of metamorphism of dry snow. Journal of Geophysical Research: Oceans, 88(C9):5475-5482.

Conway, H. and Benedict, R. (1994). Infiltration of water into snow. Water Resources Research, 30(3):641-649.

Dingman, S. L. (2015). Physical Hydrology. Waveland Press. 
Eiriksson, D., Whitson, M., Luce, C. H., Marshall, H. P., Bradford, J., Benner, S. G., Black, T., Hetrick, H., and McNamara, J. P. (2013). An evaluation of the hydrologic relevance of lateral flow in snow at hillslope and catchment scales. Hydrological Processes, 27(5):640-654.

Evans, S. L., Flores, A. N., Heilig, A., Kohn, M. J., Marshall, H.-P., and McNamara, J. P. (2016). Isotopic evidence for lateral flow and diffusive transport, but not sublimation, in a sloped seasonal snowpack, idaho, usa. Geophysical Research Letters, 43(7):3298-3306.

Friedman, I. (1991). Isotopic changes during snow metamorphism. Stable isotope geochemistry: a tribute to Samuel Epstein.

Gustafson, J. R., Brooks, P., Molotch, N., and Veatch, W. (2010). Estimating snow sublimation using natural chemical and isotopic tracers across a gradient of solar radiation. Water Resources Research, 46(12).

Hood, E., Williams, M., and Cline, D. (1999). Sublimation from a seasonal snowpack at a continental, mid-latitude alpine site. Hydrological Processes, 13(1213):1781-1797.

Ingólfsson, Ö. and Grímsdóttir, H. (2008). The sm4 snowpack temperature and snow depth sensor. In Proceedings Whistler 2008 International Snow Science Workshop September 21-27, 2008, page 808.

Kattelmann, R. and Elder, K. (1991). Hydrologic characteristics and water balance of an alpine basin in the sierra nevada. Water Resources Research, 27(7):1553-1562. 
Luce, C. and Black, T. (2018). Personal communication on the thermocouple array at bogus basin. Personal Communications.

Marks, D. and Dozier, J. (1992). Climate and energy exchange at the snow surface in the alpine region of the sierra nevada: 2. snow cover energy balance. Water Resources Research, 28(11):3043-3054.

McClung, D. and Schaerer, P. A. (2009). The avalanche handbook. Mountaineers Books.

Sommerfeld, R. and LaChapelle, E. (1970). The classification of snow metamorphism. Journal of Glaciology, 9(55):3-18.

Sturm, M., Holmgren, J., König, M., and Morris, K. (1997). The thermal conductivity of seasonal snow. Journal of Glaciology, 43(143):26-41. 
APPENDIX A:

\section{TIME-LAPSE MOVIES}




\section{A.1 Early Season}

https://youtu.be/f_LF7-_opkc

\section{A.2 Mid Season}

https://youtu.be/J5fFBARJAu0

\section{A.3 Late Season - Isothermal Development}

https://youtu.be/hLevt5xeN9o 
APPENDIX B:

\section{BSTA TECHNICAL DETAILS}




\section{B.1 Parts List}

https://drive.google.com/file/d/1wrSelvj6EzlNViaM0zonwLIbumqkNpm5/

view? $\mathrm{usp}=$ sharing

\section{B.2 CR1000 Code}

https://drive.google.com/file/d/1Z6SDvXJ5vwWH153xJffSQQ8yu ${ }_{D} a K K H o /$ view?usp $=$ sharing

\section{B.3 Structure Design}

The Banner Summit Thermocouple Array is based off designs shared by Charlie Luce and Tom Black during correspondence on October 18th, 2018. We used these diagrams to design and construct the BSTA frame as seen in the below figure. Thin wires run between the two 3" channel vertical supports every $5 \mathrm{~cm}$ and are attached to eye-bolts on each of the vertical supports. Each of these wires supports a thermocouple and is kept taught by springs on each of the eye-bolts. A $1.25 \mathrm{~m} \times 1.25 \mathrm{~m}$ square of 3" channel is attached to the vertical supports and burried just below the soil to act as a foundation for the instrument. 


\section{Banner Summit Thermocouple Array Structure}

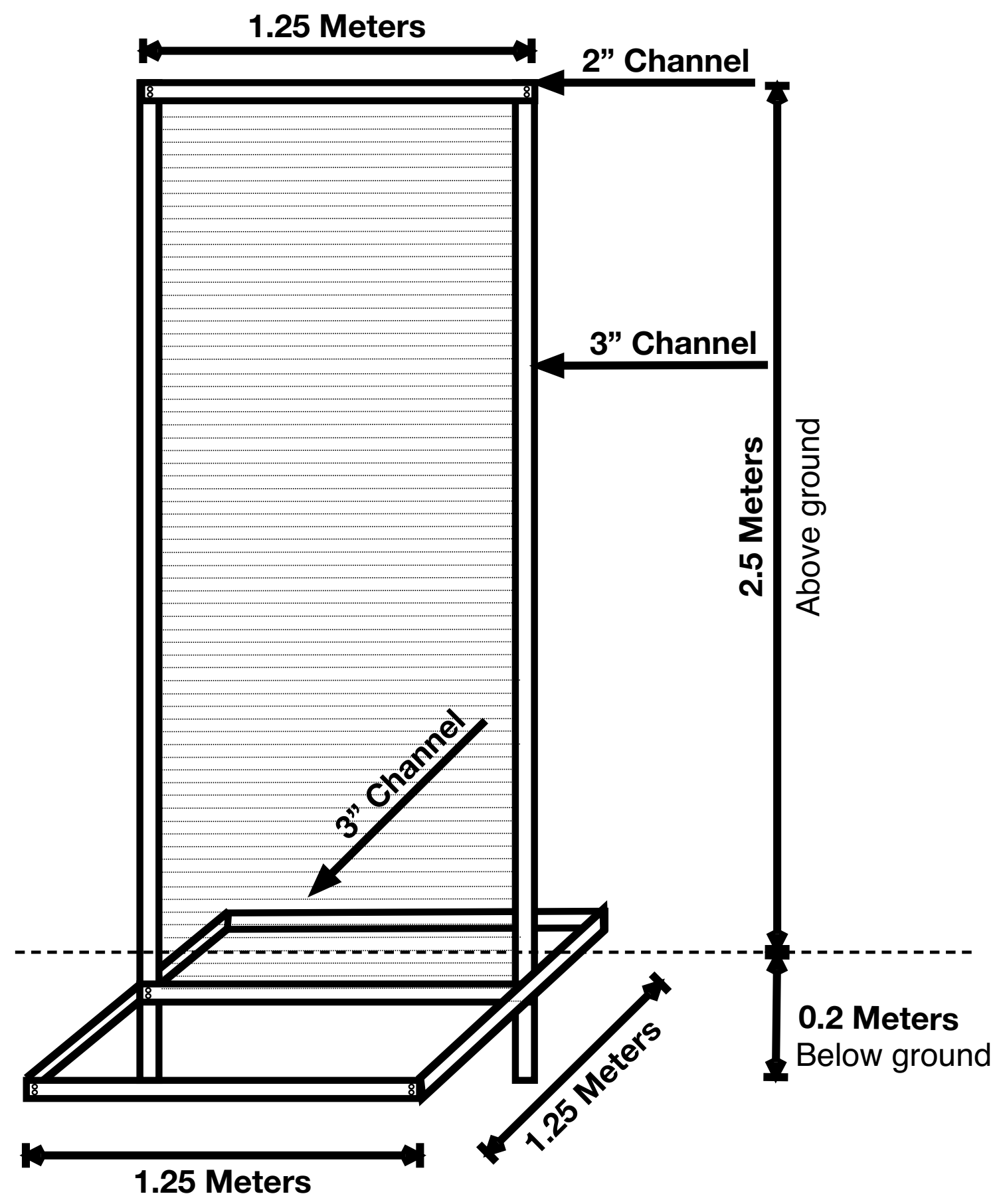


APPENDIX C:

\section{DATA \& ANALYSIS}




\section{C.1 Water Year 2019 Data}

https://drive.google.com/file/d/1S0TLIX7pi3IJApxP7INtTE2Y9EOZIk_5/view?

usp=sharing

\section{C.2 Water Year 2020 Data}

\section{C.2.1 Raw Transmitted Data}

Transmitted data from 2020 can be found via this link:

http://denali.micro-specialties.com/cgi-bin/globalModemData.cgi?

site $=$ sn314start $=2020 / 2 / 1$

\section{C.2.2 2020 Data Intake (Python)}

Here is a Python script that collects transmitted data and conducts basic visualization: https://drive.google.com/file/d/1bp4srHlA0cArIyqv09bc1su8xadS9i5j/ view? usp=sharing

\section{C.3 Analysis}

Below are links to the MATLAB scripts used to conduct analysis on temperature gradients, uncertainty, and runoff timing. They are all compatable with the Water Year 2019 data found in Appendix C.1.

\section{C.3.1 Temperature Gradient Analysis}

https://drive.google.com/file/d/1q9dmvjT9bsjzyus962ExAWQKkBX-zMRJ/

view? usp=sharing 


\section{C.3.2 Uncertainty Analysis}

https://drive.google.com/file/d/1h 1 s3D6DkYiPE2lqnu2pnMlw3HFXLCw/ view?usp $=$ sharing

C.3.3 Isothermal Snowpack and Runoff Timing

https://drive.google.com/file/d/1dVCQnMA9SbabyH32f5AAHxmj1dchDZLI/ view? usp $=$ sharing 


\section{APPENDIX D:}

\section{STABLE WATER ISOTOPE ANALYSIS}




\section{D.1 Literature Review}

Stable water isotopes can be used to better understand snow hydrological processes (Beria et al. (2018)). The effect of different snow ablation processes (sublimation, melting, and redistribution) can be seen in the isotopic evolution of a seasonal snowpack (Beria et al. (2018)). Water Isotopes represent a potential independent measure of sublimation in seasonal snow cover, although the majority of work in this area has focused on hydrograph separation (Gustafson et al. (2010)). Sommerfel (1987) and Gustafson (2010) found that isotope fractionation, driven by high vapor pressure deficits, could be a sensitive tool for determining relative mass change in a column of snow. However, other studies have failed to prove the ability of water isotopes to gauge water loss due to sublimation (Friedman (1991)).

Spatial precipitation patterns, preferential snow deposition, and wind redistribution lead to heterogeneous snow accumulation patterns (Beria et al. (2018)). Complex interactions among snow ablation, topography, and vegetation lead to more spatial heterogeneity of snow packs (Beria et al. (2018)). The spatial variability associated with snowpack stable water isotopes poses a significant challenge when using it as an independent measure of sublimation in seasonal snow cover.

\section{D.2 Methods}

Snow was sampled within 20 meters of the Banner Summit SNOTEL site for analysis of stable water isotopes. The snow pit locations are randomly selected on a flat surface with no apparent aspect. The sampled area is lightly forested, but care is taken in order to prevent contamination from secondary snow input such as fallen, intercepted snow or wind drifts. In order to capture the full isotopic content of a 
snowpack, samples were collected from the whole snow profile with a $3 \mathrm{~cm}$ vertical resolution. To assess spatial variability of stable water isotopes, duplicate samples were collected from one pit with about $0.5 \mathrm{~m}$ horizontal spacing (figure D.1). To assess systematic bias in the sampling method, samples were collected in triplicates directly adjacent to each other (figure D.2). Detailed notes are taken on snowpack characteristics during each sampling event.

Snow samples are transported back to Boise State University where they are stored at $-20^{\circ} \mathrm{C}$. A fourth generation (purchased 2011) Los Gatos Research (LGR) Liquid Water Isotope Analyzer (LWIA) is used to measure ${ }^{2} \mathrm{H} /{ }^{1} \mathrm{H}$ and ${ }^{18} \mathrm{O} /{ }^{16} \mathrm{O}$ for all snow samples. Results are reported in units of per mil (\%o), relative to Vienna Standard Mean Ocean Water (VSMOW). Raw LWIA values are processed using the Los Gatos Research post-processing software. 


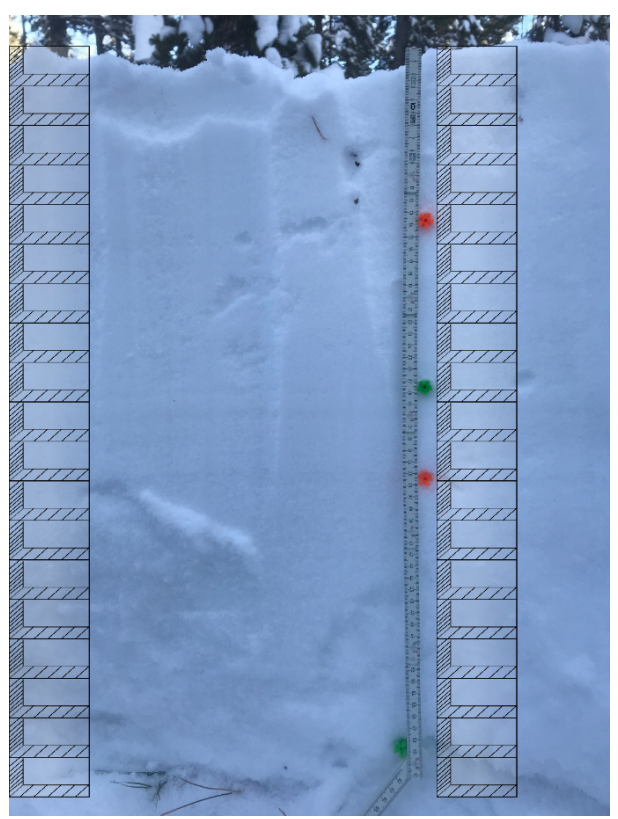

Figure D.1: Picture of the sampling pit used on December 18, 2018 illustrating where duplicates were sampled with about $0.5 \mathrm{~m}$ spacing as represented by the shaded boxes with black lines. The red and green dots are observed ice layers, and storm layer surfaces. 


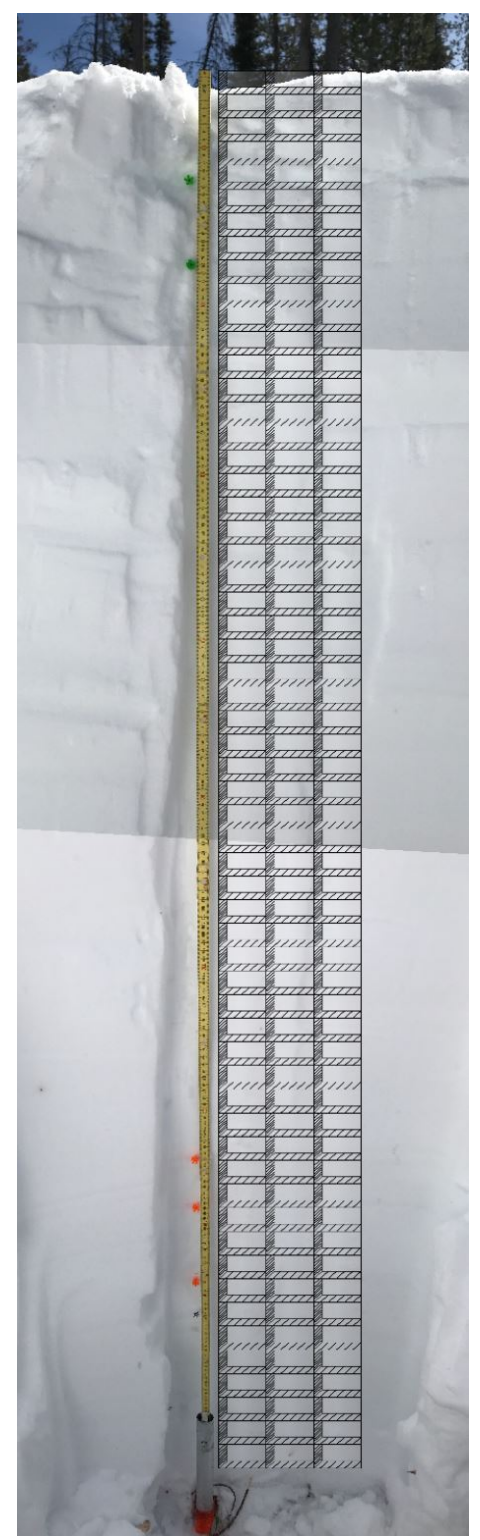

Figure D.2: Picture of the sampling pit used on March 17th, 2019 showing where triplicates were collected.

\section{D.3 Results}

Early in the season, duplicate snow samples were taken from a single pit, but with 0.5m horizontal spacing (D.1). This resulted in significant differences (up to 50\%) in 
stable isotopes near the top of the snowpack (D.3). The variation between duplicates was much lower in the bottom of the snowpack. Similar trends are present in each duplicate, just displaced with respect to depth. Later in the season, Mar. 17th, triplicate samples were taken directly adjacent to each other (D.2) and the results suggest very little variation between triplicates with a maximum difference of $13 \%$ (D.4). 


\section{$\delta 180$ With Snow Depth}

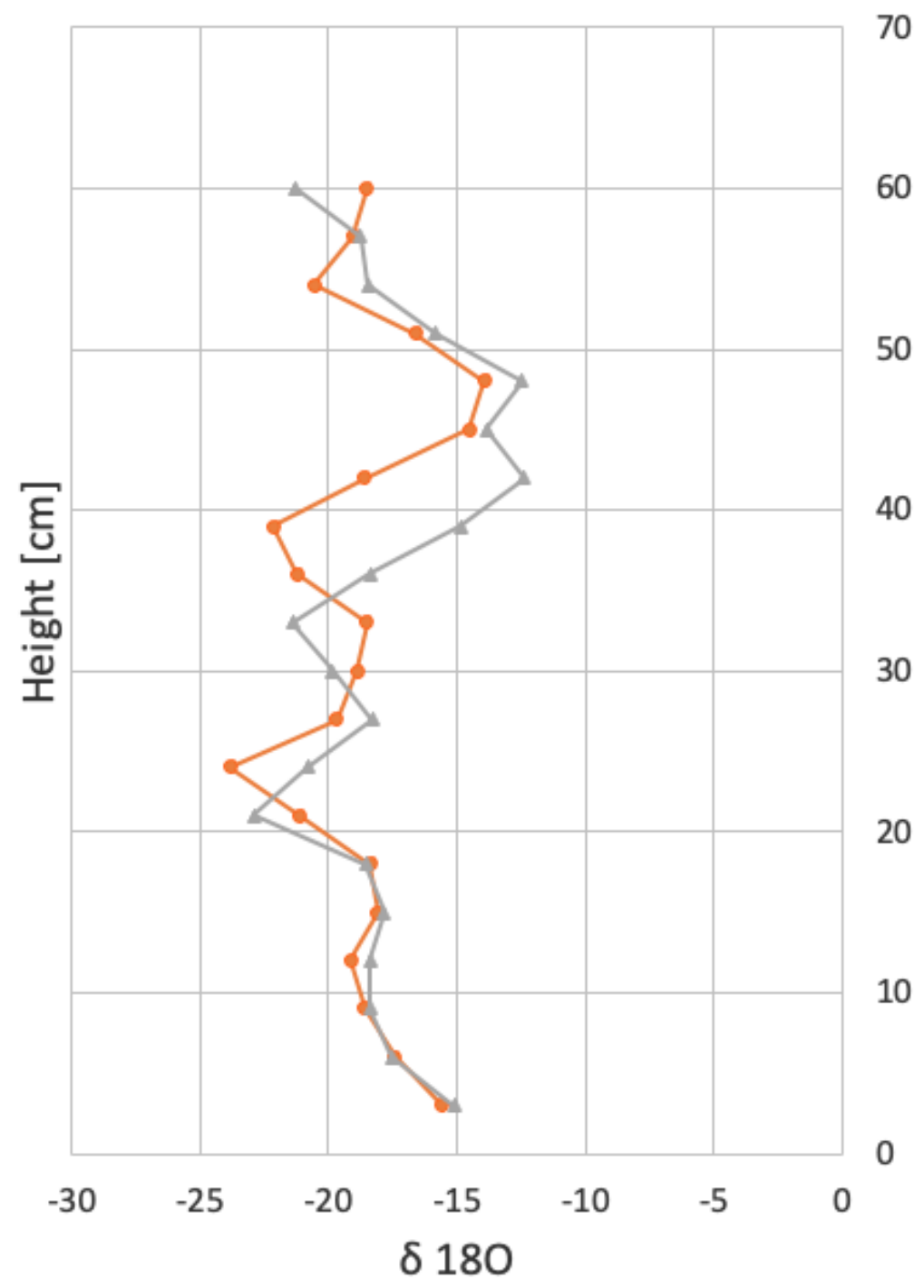

$\longrightarrow$ 18-Dec-18 $\longleftarrow$ 18-Dec-18

Figure D.3: Stable water isotope composition for samples taken on December 18, 2018. There is strong agreement in the lowest $10 \mathrm{~cm}$, but the profiles diverge moving up through the snowpack. The largest difference between profiles is right around $40 \mathrm{~cm}$. 


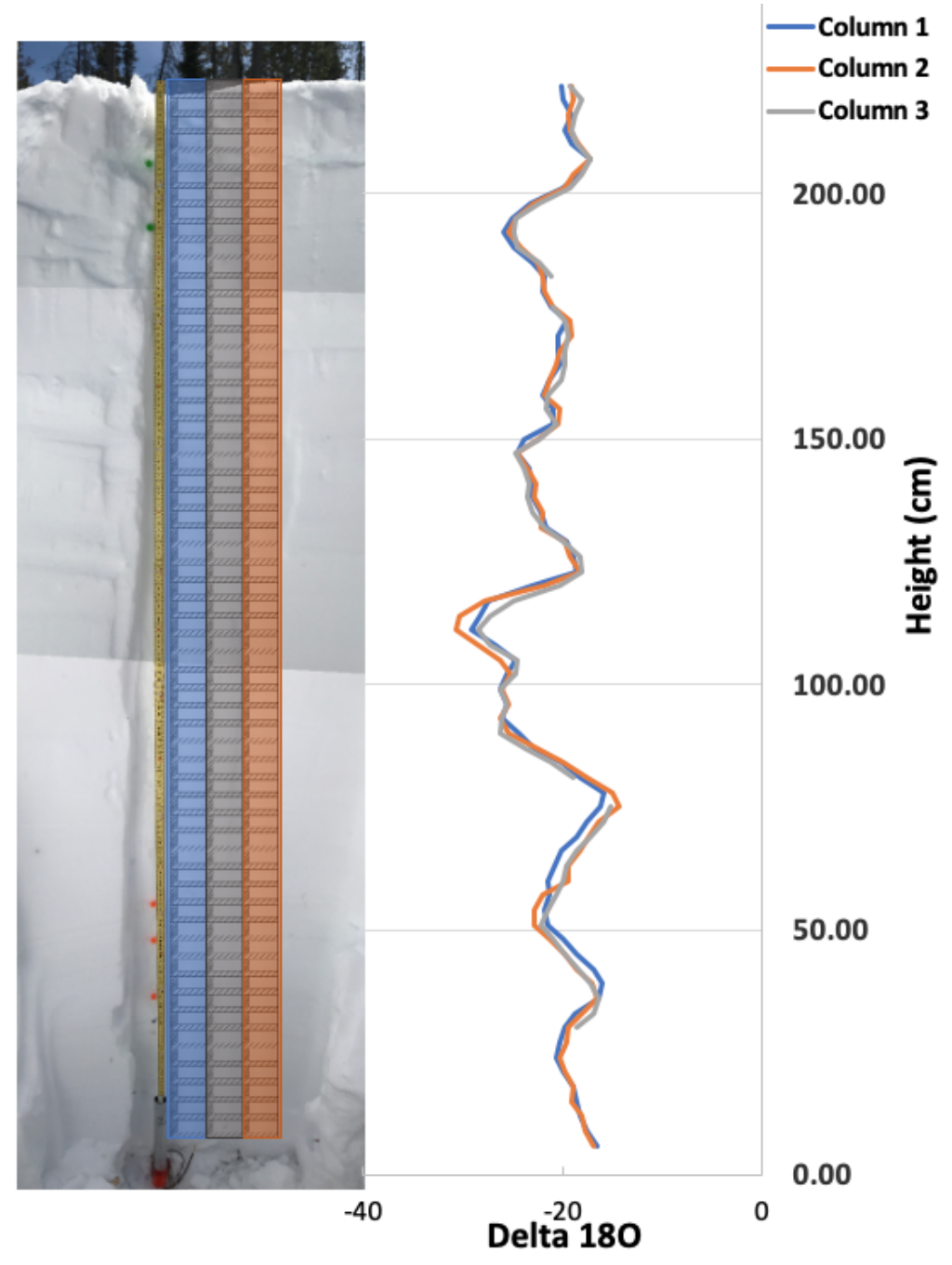

Figure D.4: Stable water isotope composition for samples taken on March $17,2019$.

\section{D.4 Discussion}

Samples for stable isotope analysis were collected in a lightly forested area with varying amounts of underbrush and fallen trees. This uneven ground creates an inconsistent datum between sampling events and introduces an unexpected amount of spatial variability. In addition to this, the presence of vegitation also affects snow processes 
via emission of longwave radiation, screening of solar radiation, etc (Beria et al. (2018). Moving forward, sampling for stable water isotopes in snow should be conducted in open areas with an even ground surface that is free of large brush, or fallen debris. If a study is conducted in a forested/lightly forested area, there should be a preseason effort to clear the sampling locations of anything that creates an uneven ground surface.

Although this dataset does not provide a basis for conclusions that differ from previous studies, there are important trends to note. Figure D.5 shows samples taken

from three different days accross the season. The $\delta^{18} \mathrm{O}$ values are more consistent in the lowest portion of the snowpack and diverge upwards.

\section{D.5 Conclusions}

Any time there is a phase change with subsequent migration of water molecules, the stable water isotope concentrations of the remaining snow is altered. Measuring this change in stable isotope concentrations over time could improve our current understanding of internal snowpack processes. Future work should focus on reducing the error associated with sampling snow over a sizeable temporal domain. Improving our identification of specific storm layers will increase our ability to correlate between sampling events and will improve our ability to interpret this data. Additionally, establishing a snow sampling regime with a consistent datum, or ground surface, will reduce the error. 


\section{$\delta 180$ With Snow Depth}

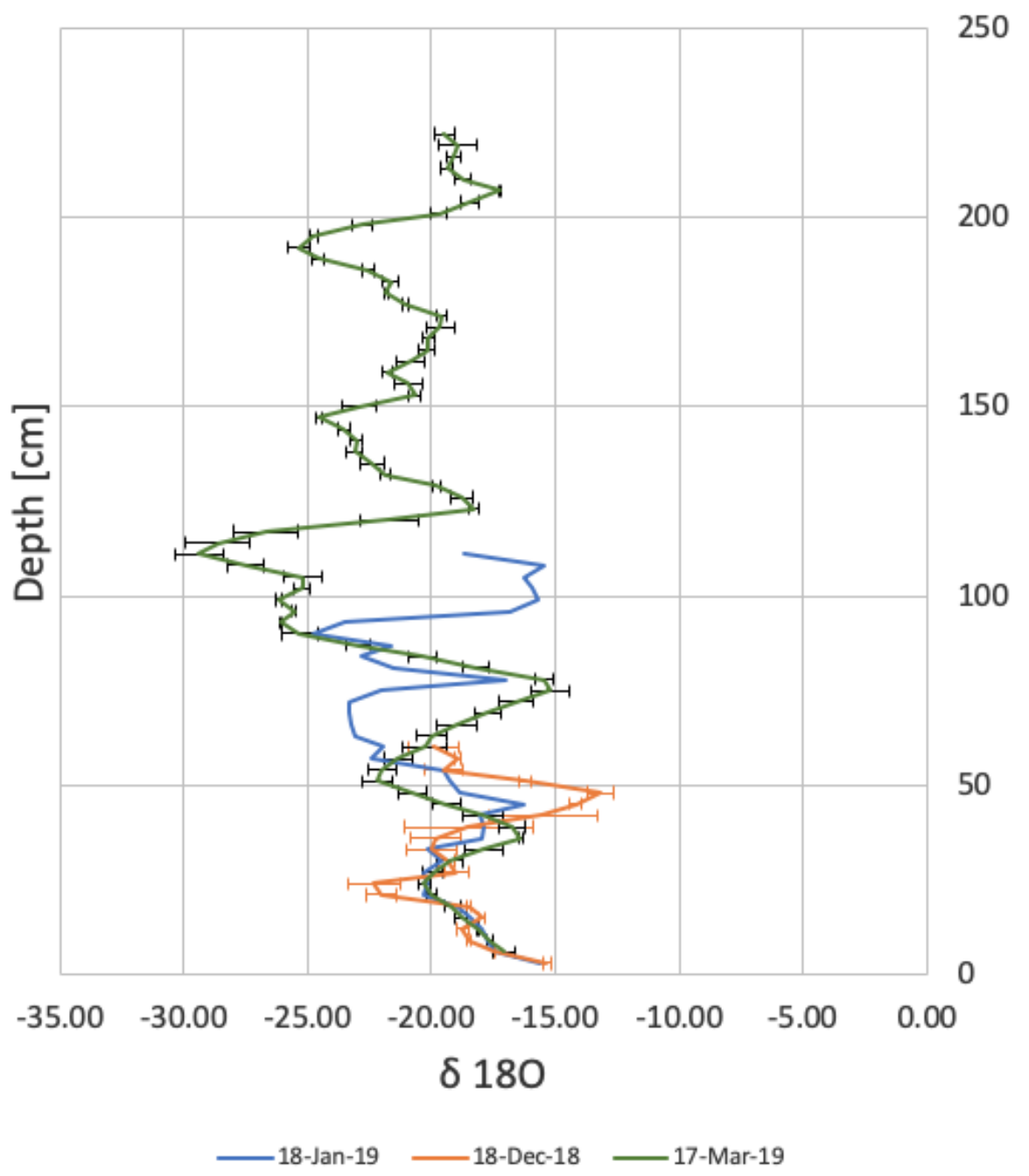

Figure D.5: Oxygen isotopes sampled throughout the 2019 winter season. 